\title{
Measurements of Humidity in the Atmosphere and Validation Experiments (MOHAVE)-2009: overview of campaign operations and results
}

\author{
T. Leblanc ${ }^{1}$, T. D. Walsh ${ }^{1}$, I. S. McDermid ${ }^{1}$, G. C. Toon ${ }^{2}$, J.-F. Blavier ${ }^{2}$, B. Haines ${ }^{2}$, W. G. Read ${ }^{2}$, B. Herman ${ }^{2}$, \\ E. Fetzer ${ }^{2}$, S. Sander ${ }^{2}$, T. Pongetti' ${ }^{2}$, D. N. Whiteman ${ }^{3}$, T. G. McGee ${ }^{3}$, L. Twigg ${ }^{3}$, G. Sumnicht ${ }^{3}$, D. Venable ${ }^{4}$, \\ M. Calhoun ${ }^{4}$, A. Dirisu ${ }^{5}$, D. Hurst ${ }^{6}$, A. Jordan ${ }^{6}$, E. Hall ${ }^{6}$, L. Miloshevich ${ }^{7}$, H. Vömel ${ }^{8}$, C. Straub ${ }^{9}$, N. Kampfer ${ }^{9}$, \\ G. E. Nedoluha ${ }^{10}$, R. M. Gomez ${ }^{10}$, K. Holub ${ }^{11}$, S. Gutman ${ }^{11}$, J. Braun ${ }^{12}$, T. Vanhove ${ }^{12}$, G. Stiller ${ }^{13}$, and \\ A. Hauchecorne ${ }^{14}$ \\ ${ }^{1}$ Jet Propulsion Laboratory, California Institute of Technology, Wrightwood, CA 92397, USA \\ ${ }^{2}$ Jet Propulsion Laboratory, California Institute of Technology, Pasadena, CA, USA \\ ${ }^{3}$ NASA Goddard Space Flight Center, Greenbelt, MD 20771, USA \\ ${ }^{4}$ Howard University, Beltsville, MD, USA \\ ${ }^{5}$ NASA/Oak Ridge Associated Universities, USA \\ ${ }^{6}$ Cooperative Institute for Research in Environmental Sciences, University of Colorado, Boulder, CO; NOAA Earth System \\ Research Laboratory, Global Monitoring Division, Boulder, CO 80305, USA \\ ${ }^{7}$ Milo Scientific LLC, Lafayette, CO 80026, USA \\ ${ }^{8}$ Deutscher Wetterdienst, Richard Aßmann Observatory, Lindenberg, Germany \\ ${ }^{9}$ Institute of Applied Physics, University of Bern, Switzerland \\ ${ }^{10}$ Naval Research Laboratory, Code 7227, Washington, DC 20375, USA \\ ${ }^{11}$ NOAA Earth System Research Laboratory, Boulder, CO 80305, USA \\ ${ }^{12}$ UCAR, National Centre for Atmospheric Research, Boulder, CO 80305, USA \\ ${ }^{13}$ Karlsruhe Institute of Technology, Institute for Meteorology and Climate Research, Karlsruhe, Germany \\ ${ }^{14} \mathrm{CNRS} / \mathrm{IPSL} / \mathrm{LATMOS}$, France
}

Received: 22 April 2011 - Published in Atmos. Meas. Tech. Discuss.: 31 May 2011

Revised: 1 November 2011 - Accepted: 2 November 2011 - Published: 1 December 2011

\begin{abstract}
The Measurements of Humidity in the Atmosphere and Validation Experiment (MOHAVE) 2009 campaign took place on 11-27 October 2009 at the JPL Table Mountain Facility in California (TMF). The main objectives of the campaign were to (1) validate the water vapor measurements of several instruments, including, three Raman lidars, two microwave radiometers, two Fourier-Transform spectrometers, and two GPS receivers (column water), (2) cover water vapor measurements from the ground to the mesopause without gaps, and (3) study upper tropospheric humidity variability at timescales varying from a few minutes to several days.
\end{abstract}

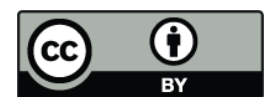

Correspondence to: T. Leblanc (leblanc@tmf.jpl.nasa.gov)
A total of 58 radiosondes and 20 Frost-Point hygrometer sondes were launched. Two types of radiosondes were used during the campaign. Non negligible differences in the readings between the two radiosonde types used (Vaisala RS92 and InterMet iMet-1) made a small, but measurable impact on the derivation of water vapor mixing ratio by the FrostPoint hygrometers. As observed in previous campaigns, the RS92 humidity measurements remained within $5 \%$ of the Frost-point in the lower and mid-troposphere, but were too dry in the upper troposphere.

Over $270 \mathrm{~h}$ of water vapor measurements from three Raman lidars (JPL and GSFC) were compared to RS92, CFH, and NOAA-FPH. The JPL lidar profiles reached $20 \mathrm{~km}$ when integrated all night, and $15 \mathrm{~km}$ when integrated for $1 \mathrm{~h}$. Excellent agreement between this lidar and the frost-point hygrometers was found throughout the measurement range,

Published by Copernicus Publications on behalf of the European Geosciences Union. 
with only a $3 \%(0.3 \mathrm{ppmv})$ mean wet bias for the lidar in the upper troposphere and lower stratosphere (UTLS). The other two lidars provided satisfactory results in the lower and midtroposphere (2-5\% wet bias over the range $3-10 \mathrm{~km})$, but suffered from contamination by fluorescence (wet bias ranging from 5 to $50 \%$ between $10 \mathrm{~km}$ and $15 \mathrm{~km}$ ), preventing their use as an independent measurement in the UTLS.

The comparison between all available stratospheric sounders allowed to identify only the largest biases, in particular a $10 \%$ dry bias of the Water Vapor Millimeterwave Spectrometer compared to the Aura-Microwave Limb Sounder. No other large, or at least statistically significant, biases could be observed.

Total Precipitable Water (TPW) measurements from six different co-located instruments were available. Several retrieval groups provided their own TPW retrievals, resulting in the comparison of 10 different datasets. Agreement within $7 \%(0.7 \mathrm{~mm})$ was found between all datasets. Such good agreement illustrates the maturity of these measurements and raises confidence levels for their use as an alternate or complementary source of calibration for the Raman lidars.

Tropospheric and stratospheric ozone and temperature measurements were also available during the campaign. The water vapor and ozone lidar measurements, together with the advected potential vorticity results from the high-resolution transport model MIMOSA, allowed the identification and study of a deep stratospheric intrusion over TMF. These observations demonstrated the lidar strong potential for future long-term monitoring of water vapor in the UTLS.

\section{Introduction}

Water vapor is well known for its radiative, chemical, and thermo-dynamical significance in all layers of the atmosphere from the ground to the mesosphere (e.g., Forster and Shine, 1999). In the troposphere, it is the second most important greenhouse gas after carbon dioxide, and in the stratosphere, it is produced by methane oxidation thus linking it to ozone chemistry. Despite its abundance in the lower troposphere, its rarity in the upper troposphere and lower stratosphere (UTLS) makes measurement there very challenging. The sensitivity of operational radiosonde sensors suffers under conditions of very low ambient temperatures and relative humidities, limiting the range of quality measurements to the low and middle troposphere (Miloshevich et al., 2004, 2009). Research-grade balloon-borne frost-point hygrometers remain the best source of high quality water vapor measurements in the UTLS (Vömel et al., 2007a) but are too expensive to be used on operational basis. Satellite measurements uncertainty remains high near the tropopause due to the abrupt change of mixing ratio below the tropopause (Read et al., 2007). As a result, many aspects of water vapor variability in the UTLS are yet to be fully explained, two ex- amples being the continuing debate on water vapor transport into the tropical lower stratosphere (Fueglistaler et al., 2009), and the slow increase of lower stratospheric water vapor mixing ratio during the last decade of the 20th century followed by a decrease in 2001-2006 and again a slight increase since 2006 (Oltmans et al., 2000; Randel et al., 2006; Hurst et al., 2011a).

In the early 2000s, the international Network for the Detection of Atmospheric Composition Change (NDACC, formerly known as NDSC) considered the inclusion of water vapor Raman lidar in its suite of high quality instruments and techniques. A number of ground-based Raman lidars were specifically built for measurements of water vapor reaching the LS (Leblanc et al., 2008; Whiteman et al., 2010). To assure the best available quality, the NDACC protocols require thorough validation of all instruments before their official affiliation to the network and routine archiving of the data. Several validation campaigns were therefore performed. The first two MOHAVE (Measurement of Humidity in the Atmosphere and Validation Experiments) campaigns took place at the JPL Table Mountain Facility (TMF, $34.4^{\circ} \mathrm{N}, 117.7^{\circ} \mathrm{W}$, elevation: $2300 \mathrm{~m}$ ) in October 2006 and 2007. They were dedicated to the validation of the measurements of water vapor in the UTLS obtained by three new Raman lidars. These campaigns were successful as they exposed issues that needed to be addressed before the technique would become mature enough for NDACC, i.e., the need for stable calibration techniques over extended time periods, the removal of fluorescence contaminating the lidar signals, and further optimization of the signal-to-noise ratios.

The MOHAVE-2009 campaign was an extension of the MOHAVE and MOHAVE-2 campaigns. Though lidar validation had again triggered the planning of the campaign, many other instruments and techniques joined the intercomparison efforts, leading to one of the most extensive atmospheric water vapor validation campaign ever undertaken. The main goal of the campaign was to validate the water vapor measurements of several Raman lidars, two microwave radiometers, two types of operational radiosondes, two types of Frost-Point hygrometers, two Fourier-Transform Spectrometers, two microwave radiometers, and two Global Positioning System (GPS) receivers. Measurements from five satellite instruments (ACE, AIRS, MIPAS, MLS, TES) were also included in the set of correlative data. Another goal of the campaign was to provide water vapor profiles from the ground to the mesopause without gaps. The third and last objective was to study water vapor variability in the UTLS in connection with the position of the subtropical jet near TMF. All three objectives were successfully met, and a review of the results is presented herein.

After a brief review of the participating instruments (Sect. 2) and campaign operations (Sect. 3), results from a variety of instruments and techniques are presented (Sect. 4). A synthesis of these results is presented in the last section (Sect. 5). Detailed instrument descriptions and validation 
results are presented in other papers in this special issue on MOHAVE-2009 (Hurst et al., 2011b; McDermid et al., 2011; Leblanc et al., 2011a; McGee et al., 2011; Stiller et al., 2011; Whiteman et al., 2011; Toon et al., 2011)

\section{Participating instruments}

A large suite of baloon-borne in situ, ground-based active and passive remote sensing instruments and techniques were used during the campaign. The basic characteristics of these instruments are compiled in Table 1. Additional information can be found on the following MOHAVE-2009 webpage: http://tmf-lidar.jpl.nasa.gov/ campaigns/mohave2009/Instruments_Species.htm

\subsection{Frost-Point Hygrometers}

The Frost-Point Hygrometry technique (Brewer et al., 1948; Barrett et al., 1950) is based upon the well-known equilibrium thermodynamics (Clausius-Clapeyron) of ice (frost) and overlying water vapor. Frost-point hygrometers actively maintain the equilibrium of this two phase system by continuously adjusting the temperature of a frost layer such that it remains stable. Both the NOAA/Earth System Research Laboratory Frost Point Hygrometer (NOAA-FPH) and the Cryogenic Frost-Point Hygrometer (CFH) use optical detection of the frost layer on a small mirror. A feedback loop actively regulates the mirror temperature to maintain a stable frost layer, making the water vapor content of the overlying air directly calculable from the frost point temperature.

The balloon borne NOAA-FPH has been used in Boulder, Colorado since 1980 (Vömel et al., 1995), producing the longest stratospheric water vapor record in existence (Hurst et al., 2011a). It has also been flown from Lauder, New Zealand since 2004 and has been part of a number of tropical, mid-latitude and polar measurement campaigns (Kley et al., 1997). The measurement uncertainty for this instrument is largely determined by the stability of the frost layer and under optimal performance is around $0.5 \mathrm{~K}$ in frost-point temperature. This translates to about $10 \%$ uncertainty in mixing ratio at stratospheric values. This instrument in its many iterations since 1980 has relied on the same measurement principle and calibration process to assure long-term measurement accuracy. The routine NOAA-FPH soundings over Boulder revealed the long-term increasing trend of stratospheric water vapor between 1980 and 2000 (Oltmans and Hofmann, 1995; Oltmans et al., 2000) and beyond (Hurst et al., 2011a).

The CFH was developed at the University of Colorado (Vömel et al., 2007a). It is similar in principle to the NOAAFPH, with only minor differences from the NOAA instrument version used during MOHAVE-2009. The measurement uncertainty of the $\mathrm{CFH}$ is less than $0.5 \mathrm{~K}$ throughout the entire profile, which translates to conservative mixing ratio uncertainty values of $4 \%$ in the lower troposphere and $9 \%$ in the stratosphere. The $\mathrm{CFH}$ has been used in a number of intercomparison experiments (e.g., Miloshevich et al., 2006; Vömel et al., 2007a), in stratospheric and tropospheric satellite validation observations (e.g., Read et al., 2007; Vömel et al., 2007b; Fetzer et al., 2008), a large number of scientific observational campaigns (e.g., Hasebe et al., 2007; Shibata et al., 2007), and is currently in routine operation at Sodankyla, Finland; Alajuela, Costa Rica; and Lindenberg, Germany.

Though both the CFH and NOAA-FPH provide a mixing ratio profile during both balloon ascent and descent, the best quality measurements for $\mathrm{CFH}$ take place during ascent, while the best quality measurements for NOAA-FPH take place during descent to avoid any potential errors caused by outgassing from the balloon (Hurst et al., 2011b). In the UTLS, the Frost-Point Hygrometer was considered the most reliable technique participating to MOHAVE-2009. It will therefore be considered the reference in this region throughout this paper. Sixteen CFH and four NOAA-FPH were launched over the 2-week period of the campaign. A thorough description of these instruments and their results is provided in Hurst et al. (2011b).

\subsection{Radiosondes}

Two types of meteorological radiosondes, designed for worldwide use on operational basis, were launched during MOHAVE-2009, namely the InterMet iMet-1 and Vaisala RS92 radiosondes.

The iMet-1 radiosonde is a first generation PTU (Pressure Temperature Humidity) radiosonde developed by InterMet. Due to its early stage of development at the time of the campaign, the water vapor measurements were of poor quality and will not be presented, nor discussed in this paper. The radiosonde performed reasonably well for pressure and temperature and results will be shown. An improved version of iMet-1 radiosonde from this manufacturer is now in use.

The Vaisala RS92 radiosonde introduced in 2004 is based on thin-film technology (Salasmaa and Kostamo, 1975) and uses heated dual H-Humicap sensors similar to those of its most recent predecessor RS90. Each sensor consists of a hydro-active polymer film acting as dielectric between two electrodes applied on a glass substrate. The response time of the sensor is dependent on the polymer's ability to adsorb and desorb water vapor and is strongly dependent on temperature. Changes over time in the RS92 design have been documented by Vaisala and can be identified for each radiosonde serial number by visiting their website. The RS92 radiosondes were tested during many field campaigns (e.g., Miloshevich et al., 2006, 2009; Suortti et al., 2008). Measurement uncertainty includes mean calibration bias, solar radiation error (daytime only), production variability (random error), sensor time-lag (which effect is to smooth out sharp vertical features), ground-check-induced biases, and rounding (for standard factory processing only). Time-lag and empirical bias correction following the method described by Miloshevich 
Table 1. Overview of the participating MOHAVE-2009 water vapor instruments.

\begin{tabular}{|c|c|c|c|c|c|c|}
\hline $\begin{array}{l}\text { Instrument } \\
\text { Short Name }\end{array}$ & Instrument Type & Team & Measur.Type & VerticalRange & Remarks & Reference \\
\hline ALVICE & Raman Lidar & (Whiteman) & Profile & $3-20 \mathrm{~km}$ & Nighttime only & Whiteman et al. (2010) \\
\hline STROZ & Raman Lidar & (McGee) & Profile & $3-17 \mathrm{~km}$ & Nighttime only & McGee et al. (1991) \\
\hline TMW & Raman Lidar & JPL-TMF & Profile & $3-20 \mathrm{~km}$ & Nighttime only & Leblanc et al. (2008) \\
\hline Vaisala RS92 & PTU Radiosonde & GSFC (Whiteman) & Profile & Ground-18 km & Balloon & Whiteman et al. (2011) \\
\hline Vaisala RS92 & PTU Radiosonde & JPL-TMF & Profile & Ground-18 km & Balloon & Miloshevich et al. (2009) \\
\hline $\mathrm{CFH}$ & Frost-Point Hygrometer & DWD & Profile & Ground-30 km & Balloon & Vömel et al. (2011) \\
\hline NOAA-FP & Frost-Point Hygrometer & NOAA-ESRL & Profile & Ground-30 km & Balloon & Hurst et al. (2011) \\
\hline MIAWARA-C & Microwave Radiometer & Univ. $\quad$ Bern & Profile TPW & $30-75 \mathrm{~km}$ & Automated24/7 & Straub et al. (2010) \\
\hline WVMS & Microwave Radiometer & NRL & Profile TPW & $25-75 \mathrm{~km}$ & Automated24/7 & Nedoluha et al. (1995) \\
\hline Aura-MLS & Microwave Radiometer & JPL & Profile & $10-75 \mathrm{~km}$ & Satellite & Read et al. (2007) \\
\hline MIPAS & Fourier-Transform Spectrometer & Karlsruhe Inst.Tech. (KIT) & Profile & $10-70 \mathrm{~km}$ & Satellite & Stiller et al. (2011) \\
\hline AIRS & Infrared Spectrometer & JPL & Profile & Ground- $15 \mathrm{~km}$ & Satellite & Fetzer et al. (2008) \\
\hline MkIV FTIR & Fourier-Transform Spectrometer & JPL & Profile TPW & Ground-12 km & Daytime only & Schneider et al. (2010) \\
\hline FTUVS & Fourier-Transform Spectrometer & JPL & TPW & N/A & Daytime only & Cageao et al. (2001) \\
\hline SA65 & GPS & NCAR & TPW & N/A & Automated $24 / 7$ & Ware et al. (2000) \\
\hline TABV & GPS & JPL-TMF NOAA-GSD & TPW & N/A & Automated24/7 & Wolfe and Gutman (2000) \\
\hline
\end{tabular}

et al. (2009) allows extension of the useful relative humidity $(\mathrm{RH})$ measurement range from the hygropause (typically $10-12 \mathrm{~km}$ ) to an altitude of $18 \mathrm{~km}$ (cold-point tropopause or lowermost stratosphere, depending on the latitude of sounding). During daytime, dry bias caused by solar radiation is the dominant systematic error. It is strongly dependant on altitude and can reach up to $50 \%$ of the measured RH in the tropical upper troposphere (Vömel et al., 2007c).

PTU radiosondes are still the most affordable instrument for the measurement of relative humidity in the troposphere. During the campaign a total of 58 RS92 PTU radiosondes were launched (41 RS92-K and 17 RS92-SGP). In 14 cases, two RS92 were mounted on the same balloon payload ("duals") and data were received by two separate ground systems, one operated by JPL, and another operated by GSFC. Since they are required for the Frost-Point Hygrometer data telemetry, InterMet sondes were included on all payloads with $\mathrm{CFH}$ and NOAA-FPH.

\subsection{Water vapor raman lidars}

In addition to the JPL water vapor Raman lidar permanently deployed at TMF (referred to in the rest of this paper as "TMW"), MOHAVE-2009 hosted two mobile lidar systems from the NASA-Goddard Space Flight Center (GSFC), referred to hereafter as "ALVICE" and "STROZ" lidars.

TMW is a high-capability water vapor Raman lidar (Leblanc et al., 2008; McDermid et al., 2011) built and optimized specifically for the measurement of water vapor in the upper troposphere and lower stratosphere. It comprises a $\mathrm{Nd}$ :YAG laser with a high pulse energy of $650 \mathrm{~mJ}$ at $355 \mathrm{~nm}$, a large telescope ( $0.91 \mathrm{~m}$ diameter), and 4 small telescopes. The light Raman-shifted by nitrogen and water vapor is collected at $387 \mathrm{~nm}$ and $407 \mathrm{~nm}$ respectively. The returned signals are corrected for saturation, background noise, range, and molecular extinction. The interference by aerosol extinction is assumed to remain small $(<2 \%)$ which is true for a high altitude station like TMF. Following the classic Raman backscatter technique, the ratio of the corrected signals collected in the water vapor and nitrogen channels is proportional to water vapor mixing ratio. These profiles need calibration. This is generally obtained by scaling the uncalibrated profiles to a single (or a set of) value(s) measured externally, for example by radiosonde in the lower troposphere. The accuracy of the lidar calibration follows from that of the external source, as well as that of the correlative measurements matching method. It is generally estimated to be around $10 \%$. The water vapor profiles shown here were calibrated by estimating the best fit of the lidar profiles to the corrected RS92 measurements between 4 and $7 \mathrm{~km}$ (44 launches, RS92 correction described in Sect. 2.2). Other routine calibration methods exist, for example using the collocated ground-based measurements of Total Precipitable Water (TPW) by a GPS or microwave radiometer (Turner and Goldsmith, 1999). Taking calibration uncertainty and random noise into account and considering a 2-h integration time, the total uncertainty in the water vapor lidar profiles ranges from $5 \%$ in the lower troposphere to $15 \%$ at $12 \mathrm{~km}$, and more than $50 \%$ in the LS (estimated detection limit of 3 ppmv). The signals are vertically smoothed to mitigate the exponential increase of random noise with height, which leads to a vertical resolution ranging from $150 \mathrm{~m}$ ( 2 sampling bins) at the bottom to a few kilometers above $20 \mathrm{~km}$. A thorough description and history of the JPL water vapor lidar instrument at TMF is presented by McDermid et al. (2011).

The ALVICE system (Atmospheric Laboratory for Validation, Interagency Collaboration and Education) is a mobile facility that includes various atmospheric instruments in addition to the Raman lidar. The lidar is based on a $0.6 \mathrm{~m}$ Dall-Kirkham telescope, $16 \mathrm{~W}$ laser emitting at $50 \mathrm{~Hz}$ 
at $355 \mathrm{~nm}$, wavelength selection optics that separate the received signal into 10 optical channels that are sensed by photomultiplier tubes, and combined analog-to-digital and photon counting electronics for recording the signals. The lidar in ALVICE was originally developed for downwardlooking measurements from small research aircraft and is referred to as RASL (Raman Airborne Spectroscopic Lidar) in the airborne configuration. More detailed information on the hardware and initial measurements of the RASL system can be found in Whiteman et al. (2007). The first airborne measurements from the WAVES-2007 (Water Vapor Experiment - Satellite/Sondes) and ground-based results from the MOHAVE-2 campaign were published in Whiteman et al. (2010). The lidar now provides measurements of water vapor, several aerosol/cloud parameters (backscatter, extinction, depolarization), experimental measurements of cloud liquid (Whiteman and Melfi, 1999) or ice water content (Wang et al., 2004), and rotational Raman temperature measurements which were tested for the first time during the MOHAVE-2009 campaign. During the campaign, the lidar acquired approximately $88 \mathrm{~h}$ of measurements over 13 nights. The additional instrumentation also housed within the trailer includes a roving member of the SuomiNet GPS network providing total column water vapor (Ware et al., 2000), ground stations for the balloon-borne Vaisala RS92 and CFH instrument, and a surface meteorological system referred to as the THref (Whiteman et al., 2011). MOHAVE-2009 provided the first opportunity for all of these instruments to be deployed as a part of the mobile ALVICE system. The performance of the various components of the ALVICE system are discussed in (Whiteman et al., 2011).

The Stratospheric Ozone (STROZ) lidar has been operational since 1989 and was developed within the GSFC Stratospheric Chemistry and Dynamics Branch to be an ozone and temperature lidar validation standard for NDACC/NDSC (McGee et al., 1991, 1995). Other measurement capabilities have been added over the years (aerosols in 1992, and water vapor in 2005). Currently the lidar transmits a pair of wavelengths, $308 \mathrm{~nm}$ from a $\mathrm{XeCl}$ laser and $355 \mathrm{~nm}$ from a high powered Nd-YAG laser. The receiver consists of a pair of telescopes; a 30" main telescope with eight channels $308 \mathrm{~nm}$ ( $2 \mathrm{ch}.), 332 \mathrm{~nm}, 387 \mathrm{~nm}$ ( $2 \mathrm{ch}$.), $355 \mathrm{~nm}$ ( $2 \mathrm{ch}$.), and $407 \mathrm{~nm}$. This telescope operated during MOHAVE with a variable field-of-view (FOV): $2.3 \mathrm{mrad}$ for ozone measurements and $1.0 \mathrm{mrad}$ for water vapor measurements. The second telescope is a $4^{\prime \prime}$ Cassegrain with three channels 355 , 387 , and $407 \mathrm{~nm}$. This has a $4.5 \mathrm{mrad}$ FOV and is used to retrieve signals in the near field, roughly $500 \mathrm{~m}$ to $4 \mathrm{~km}$ above the lidar. The STROZ lidar operated in three separate modes during MOHAVE 2009. First, an ozone mode with a FOV of $2.3 \mathrm{mrad}$ and transmitting at $308 \mathrm{~nm}$ and $355 \mathrm{~nm}$ typically was used for two hours during which ozone, temperature, aerosol, and water vapor were retrieved. The second mode transmitted only $355 \mathrm{~nm}$ with the main telescope closed down to $1.0 \mathrm{mrad}$, mode during which aerosol, tem- perature, and water vapor was retrieved. The third mode consisted of transmitting only $355 \mathrm{~nm}$ with a FOV of $1.0 \mathrm{mrad}$, but with a filter, which blocked $355 \mathrm{~nm}$ while transmitting 387 and $407 \mathrm{~nm}$ radiation. The block was placed ahead of the collimation optics of the main telescope. This mode returned only water vapor data. No such filter was placed in the $4^{\prime \prime}$ receiver. The filter was used because it was shown from a previous MOHAVE campaign that fluorescence excited by the $355 \mathrm{~nm}$ within the receiver chain, although small, can (and did in the STROZ lidar case) produce a wet bias in the water vapor retrieval at high altitudes (low water vapor). The blocking filter greatly reduced but did not completely remove this interference from the STROZ data. STROZ water vapor data archived from these measurements contain only retrievals from these "blocked " data sets. A thorough description of the instrument and data is presented in (McGee et al., 2011).

Two other lidars permanently deployed at TMF and operated by JPL acquired tropospheric ozone, stratospheric ozone, and middle atmospheric temperature profiles throughout the MOHAVE-2009 campaign. The STROZ system also measured stratospheric ozone, and the ALVICE systems measured tropospheric temperature.

\subsection{Microwave radiometers}

Two ground-based microwave radiometers participated in the campaign, namely the Water Vapor Millimeter-wave Spectrometer (WVMS) permanently deployed by the US Naval Research Laboratory (NRL) at TMF (Nedoluha et al., 2011) and the portable MIddle Atmosphere WAter vapor RAdiometer (MIAWARA-C) from the University of Bern, Switzerland (Straub et al., 2010). Both instruments use the pressure broadening of the water vapor rotational transition emission line near $22 \mathrm{GHz}$ for measurements in the upper stratosphere and lower mesosphere.

NRL has operated WVMS instruments at three NDACC sites, including TMF, since the early 1990's. These instruments measures emission from the $22 \mathrm{GHz}$ water vapor transition and retrieve water vapor profiles from $\sim 40$ to $80 \mathrm{~km}$, in addition to column water. They have been shown to have good long-term stability at these altitudes (Nedoluha et al., 2009). The instrument used during MOHAVE-2009 is similar to the instrument described by Nedoluha et al. (1995) but makes use of several technological advances, including an FFT spectrometer to replace the filterbanks. While an FFT spectrometer does provide the ideal instrumental back end for retrievals in the mid-stratosphere and lower stratosphere, the incorporation of such a spectrometer does not guarantee that such measurements will be sufficiently stable to provide a useful measure of variability at these altitudes. In Nedoluha et al. (2011) it was shown that over a 5 month period from 2008-2009, the retrievals from this WVMS instrument were both consistently sensitive and stable compared to the Aura-Microwave Limb Sounder (MLS) version 2 
retrievals down to $26 \mathrm{~km}$. The standard deviation of the MLS-WVMS differences was shown to be $\sim 5 \%$ from $\sim 26-$ $70 \mathrm{~km}$ and the systematic difference was within $8 \%$ throughout this altitude range. Although the measurements shown in Nedoluha et al. (2011) showed absolute agreement with MLS to within $8 \%$ at $26 \mathrm{~km}$, uncertainties in instrumental baselines can, depending upon the shape of the baseline, lead to much larger errors. Since June 2010 WVMS retrievals at Table Mountain are being calculated after applying a constant, small $(\sim 0.06 \mathrm{~K})$ single sine-wave baseline correction without additional baseline fitting. Over 16 months (and continuing), the retrievals show good stability compared to MLS, including an increase of $\sim+0.44 \mathrm{ppmv}$ (compared to $\sim+0.27 \mathrm{ppmv}$ for coincident MLS) from JuneSeptember 2010 to June-September 2011. The longer-term stability of this baseline remains to be determined. WVMS operated quasi-continuously during MOHAVE-2009, typically retrieving daily-averaged water vapor profiles, as well as TPW measurements at 20-min intervals. Six-hour averaged profiles were also produced during MOHAVE-2009 for comparison purposes with the other campaign instruments. Unlike many ground-based microwave retrievals, no spectral fits to the instrumental baseline were included as part of the retrieval process for these measurements.

MIAWARA-C is a compact 22-GHz microwave radiometer for profile measurements of middle atmospheric water vapor specifically designed for the use in measurement campaigns. The instrument is described in detail in (Straub et al., 2010). The optical system of MIAWARA-C is designed in such a way to reduce the size of the instrument in comparison with other radiometers. For the data acquisition a digital spectrometer is used. The complete backend section, including the computer, is located in the same housing as the instrument. The receiver section is temperature stabilized to avoid gain fluctuations. Calibration of the instrument is achieved through a balancing scheme with the sky used as the cold load and the tropospheric properties are determined by performing regular tipping curves. During MOHAVE-2009, the instrument was deployed about five meters away from the WVMS radiometer described above, and acquired data continuously throughout the campaign except during the storm event of 15 October. Optimal Estimation is used for profile retrieval. The daily profiles during the MOHAVE-2009 campaign cover an altitude range between about 30 and $70 \mathrm{~km}$ with a vertical resolution of about $12 \mathrm{~km}$. The altitude range covered depends on the signal to noise ratio of the integrated spectrum, which itself depends on the tropospheric conditions. The errors in the profiles are typical for ground based $22-\mathrm{GHZ}$ water vapor radiometers. The total systematic $2-\sigma$ error, taking uncertainties from the a priori temperature information, the calibration and the spectroscopy into account, is below $16 \%$ at all altitudes, while the random error from measurement noise increases from $10 \%$ at altitudes up to $50 \mathrm{~km}$ to $25 \%$ between 50 and $70 \mathrm{~km}$.

\subsection{Fourier-Transform Spectrometers}

Two Fourier Transform Spectrometers participated in MOHAVE-2009. The portable JPL MkIV Fourier Transform Infrared (FTIR) spectrometer was deployed at TMF specifically for the campaign, while the Fourier Transform UV Spectrometer (FTUVS) is permanently deployed by JPL at TMF.

The MkIV FTIR spectrometer was designed and built at JPL in 1984 (Toon, 1991). Since then it has been operated on different platforms (ground-based, balloon-borne, and airborne) in the framework of a large variety of different campaigns mainly dedicated mainly to the investigation of stratospheric chemistry. The double-passed interferometer provides a compact design with passive shear compensation of the moving cube-corner retro-reflector. During MOHAVE 2009, the MkIV measured $0.005 \mathrm{~cm}^{-1}$ resolution spectra (maximum optical path difference of $117 \mathrm{~cm}$ ) covering a very broad spectral range $\left(650-5650 \mathrm{~cm}^{-1}\right)$. This is achieved using two liquid nitrogen-cooled detectors in parallel: an $\mathrm{HgCdTe}$ photoconductor for frequencies below $1850 \mathrm{~cm}^{-1}$ and an InSb photodiode for higher frequencies. The two detector arrangement prevents photon noise from the high frequencies, where the sun is brighter, from degrading the signals at the lower frequencies. Simultaneous highresolution measurement over such a wide spectral region imposes severe constraints on the dynamic range and linearity required of the detectors, pre-amplifiers, and signal chains. In the MkIV, this problem is addressed through the use of an 18-bit ADC module. For the MOHAVE-2009 campaign water vapor profiles were retrieved following the method described in (Schneider et al., 2010). TPW was acquired using three different retrieval methods (Toon et al., 2011).

The FTUVS has been operating at TMF since 1996 mainly observing in the UV and visible spectrum. It has the capability of operating in the range from $250 \mathrm{~nm}$ to 2.4 microns, a resolving power of over 500000 , and spectral resolution of $0.06 \mathrm{~cm}^{-1}$. The instrument system contains three subsystems: a heliostat for tracking the Sun, a beam-defining telescope, and the interferometer (Cageao et al., 2001). For $\mathrm{H}_{2} \mathrm{O}$ measurements, a long-pass optical filter with a cutoff of $1 \mu \mathrm{m}$ is placed in front of an InGaAs detector sensitive to $2.4 \mu \mathrm{m}$. Limiting the spectral operating range $\left(4170-10000 \mathrm{~cm}^{-1}\right)$ and averaging several scans improves the signal to noise ratio. For these measurements 70 scans were averaged over $30 \mathrm{~min}$ to get a SNR of a few thousand. Averaging time of the measured data can be reduced at the expense of the measurement uncertainty. Direct sun measurements were taken throughout the mostly clear sky days of the campaign. These spectra were analyzed using GFIT, a non-linear least squares retrieval algorithm that has been used for the analysis of spectra from several ground-based FTIR spectrometers (Wunch et al., 2010). The retrieved slant columns are converted to vertical columns by dividing by an air mass factor approximately equal to the secant of the solar zenith angle. The total vertical 
columns (molecule $\mathrm{mm}^{-2}$ ) are converted to IPW (mm) using the conversion $3.345 \times 10^{19}$ molecule- $\mathrm{H}_{2} \mathrm{O} \mathrm{mm}{ }^{-3}$. Measurement uncertainty is based on the spectral fitting error and the cloud cover during any given scan set and on average is $\pm 2 \%$.

\subsection{Global Positioning System (GPS)}

Atmospheric water vapor slows the propagation speed of the GPS satellite radio signal by an amount that is nearly proportional to the amount of water vapor above a GPS antenna (Bevis et al., 1992). This slowing can be expressed as either a time delay or an "excess path length" between a GPS satellite and an antenna. Geodesists interested in using GPS to monitor plate tectonic location and motion developed software packages that can estimate the excess path length given a network of GPS receivers. Three of these software packages were used during MOHAVE-2009: GAMIT, GIPSY, and Bernese. An early uncertainty analysis of GPS analysis methods (Bevis et al., 1994) indicated that estimates of PW with an accuracy of better than $2 \mathrm{~mm}$ plus $1 \%$ of the total PW amount are readily achievable using GPS observations. Continual improvements in data analysis methods have reduced this uncertainty to less than $1.0-1.5 \mathrm{~mm}$ (Mattioli et al., 2007; Thomas et al., 2011).

At TMF, the permanently deployed system "TABV" used during the campaign utilizes the same monument and antenna as the IGS site TABL, but with a different GPS receiver so that data could be obtained in near real-time. The data were processed by two different software packages, the NOAA system, known as Ground Based GPS-Met (http: //gpsmet.noaa.gov), and the NASA/JPL system using GIPSY (http://gipsy.jpl.nasa.gov). Fang and Bock (1998) defined a sliding window procedure focused on providing reliable near real-time estimates of excess path length. NOAA Research Laboratories implemented the sliding window procedure (Wolfe, 2000) using GAMIT to ascertain the impact of near real-time IPW estimates on numerical weather prediction models (Smith et al., 2007).

The GPS station SA65 is a component of the mobile NASA/GSFC ALVICE system and was deployed on the roof of the ALVICE trailer. The station is a roving member of the SuomiNet GPS network for atmospheric research (www.suominet.ucar.edu) (Ware et al., 2000) and has been used as a source of calibration for Raman water vapor lidar measurements in the past (Whiteman et al., 2006). The data are processed as part of a national network of GPS stations for atmospheric remote sensing. SuomiNet data are processed using the Bernese V5.0 GNSS analysis software (Dach et al., 2007) at the COSMIC program. During MOHAVE-2009, the instrument was operational from 9 to 27 October 2009.

\subsection{Surface meteorological measurements}

During MOHAVE-2009, surface meteorological measurements were made in support of the column and profile measurements using a variety of systems. The PTU measurements of a Vaisala Automated Weather System (MAWS) permanently deployed at TMF were used for various applications including the Vaisala RS92 radiosonde pre-launch ground check, the retrieval of TPW by microwave, and an alternate calibration method for the JPL water vapor lidar.

Measurements of surface temperature and relative humidity that are specifically suited for assessing the operational accuracy and performance of radiosonde sensors prior to launch were also acquired using the Temperature-Humidity Reference system (THref). As part of the ALVICE lidar extended instrumentation, the THref consists of six calibrated temperature and $\mathrm{RH}$ probes in a fan-ventilated chamber within a naturally-ventilated instrument shelter, into which radiosondes are placed for comparative measurements prior to launch. Analysis of the THref and RS92 raw pre-launch data gives the calibration bias of RS92 temperature and RH measurements relative to THref under surface conditions. The estimated uncertainties in the THref "best estimate" (averaged) measurements are $\pm 0.5 \% \mathrm{RH}$ and $\pm 0.1^{\circ} \mathrm{C}$. For 41 RS92-THref comparisons during the campaign, the mean and standard deviation of the RS92 temperature and RH biases were $+0.09 \pm 0.16^{\circ} \mathrm{C}$ and $+1.58 \pm 0.40 \% \mathrm{RH}$ (Miloshevich, private communication, 2011). A detailed description of the THref and its results is presented in (Whiteman et al., 2011).

Three other surface meteorological observation systems were used to support the measurements of one of the two microwave radiometers and to support the GPS measurements.

\section{Campaign operations and planning rationale}

\subsection{Measurement frequency, temporal and spatial coincidence}

A total of 44 balloons were launched over the 2-weeklong campaign. The composition of each balloon payload is detailed in Table 2. It ranges from one single RS92 PTU radiosonde (light payloads) to 2 RS92, 1 InterMet, 1 ozonesonde and 1 Frost-Point Hygrometer mounted together (heavy payloads).

Historically, the UTLS measurements from the Frost-Point Hygrometers (CFH and NOAA-FPH) have been considered to be the "reference". They will again be in this paper, but more as a convenient linkage point between all datasets rather than a "true" reference. Due to of its high cost, multiple frost-point hygrometers launches per day throughout the campaign were not possible. However, at least one launch per night, and a couple of daytime launches were performed, resulting in a total of $16 \mathrm{CFH}$ and 4 NOAA-FPH launches 
Table 2a. Summary of MOHAVE-2009 operations (11-20 October).

\begin{tabular}{|c|c|c|c|c|c|c|c|c|c|c|}
\hline $\begin{array}{l}\text { Date } \\
\text { (UT) }\end{array}$ & Lidar TMW & Lidar STROZ & Lidar ALVICE & $\begin{array}{l}\text { balloon } \\
\text { launch }\end{array}$ & $\begin{array}{l}\text { RS92 } \\
\text { K }\end{array}$ & $\begin{array}{l}\text { RS92 } \\
\text { SGP }\end{array}$ & $\mathrm{CFH}$ & $\begin{array}{l}\text { NOAA } \\
\text { FPH }\end{array}$ & FTIR MkIV & Remarks \\
\hline $\begin{array}{l}2009 \\
10 / 11\end{array}$ & $\begin{array}{l}\text { Start: 08:29 } \\
\text { End: } 10: 35\end{array}$ & - & - & $08: 23$ & $\mathrm{X}$ & $\mathrm{X}$ & TF022 & - & - & $\begin{array}{l}\text { MLS } \\
64 \mathrm{~km}, 10: 01\end{array}$ \\
\hline $\begin{array}{l}2009 \\
10 / 15\end{array}$ & Tests & Tests & Tests & 05:01 & $\mathrm{X}$ & $\mathrm{X}$ & - & - & - & Lidar tests \\
\hline $\begin{array}{l}2009 \\
10 / 16\end{array}$ & $\begin{array}{l}\text { Start: 03:46 } \\
\text { End: 09:47 } \\
- \\
-\end{array}$ & $\begin{array}{l}\text { Start: 03:17 } \\
\text { End: 09:51 } \\
- \\
-\end{array}$ & $\begin{array}{l}\text { Start: 02:26 } \\
\text { End: 09:53 } \\
- \\
-\end{array}$ & $\begin{array}{l}04: 19 \\
07: 59 \\
- \\
-\end{array}$ & $\begin{array}{l}X \\
X \\
- \\
-\end{array}$ & $\begin{array}{l}- \\
X \\
- \\
-\end{array}$ & $\begin{array}{l}- \\
- \\
- \\
-\end{array}$ & $\begin{array}{l}\text { TF024 } \\
- \\
- \\
-\end{array}$ & $\begin{array}{l}- \\
- \\
\text { Start: } 17: 05 \\
\text { End: } 22: 30\end{array}$ & $\begin{array}{l}\text { MIPAS } \\
100 \mathrm{~km}, 06: 05\end{array}$ \\
\hline $\begin{array}{l}2009 \\
10 / 17\end{array}$ & $\begin{array}{l}\text { Start: 03:11 } \\
\mid \\
\text { End: } 12: 30\end{array}$ & $\begin{array}{l}\text { Start: 02:57 } \\
\mid \\
\text { End: } 12: 30\end{array}$ & $\begin{array}{l}\text { Start: 03:05 } \\
\text { End: } 12: 18\end{array}$ & $\begin{array}{l}04: 48 \\
06: 35 \\
08: 31 \\
10: 17\end{array}$ & $\begin{array}{l}X \\
X \\
X \\
X\end{array}$ & $\begin{array}{l}X \\
- \\
X \\
-\end{array}$ & $\begin{array}{l}\text { TF025 } \\
- \\
- \\
-\end{array}$ & $\begin{array}{l}- \\
- \\
- \\
-\end{array}$ & $\begin{array}{l}- \\
- \\
- \\
-\end{array}$ & \\
\hline $\begin{array}{l}2009 \\
10 / 18\end{array}$ & $\begin{array}{l}\text { Start: 02:57 } \\
\text { End: 06:58 } \\
- \\
-\end{array}$ & $\begin{array}{l}\text { Start: 03:23 } \\
\text { End: 08:40 } \\
- \\
-\end{array}$ & $\begin{array}{l}\text { Start: 02:29 } \\
\text { End: 08:02 } \\
- \\
-\end{array}$ & $\begin{array}{l}02: 55 \\
06: 46 \\
- \\
21: 11\end{array}$ & $\begin{array}{l}- \\
X \\
- \\
X\end{array}$ & $\begin{array}{l}X \\
X \\
- \\
-\end{array}$ & $\begin{array}{l}- \\
- \\
- \\
\text { TF027 }\end{array}$ & $\begin{array}{l}\text { TF026 } \\
- \\
- \\
-\end{array}$ & $\begin{array}{l}- \\
- \\
\text { Start: } 17: 45 \\
\text { End: } 00: 15\end{array}$ & $\begin{array}{l}\text { TES-SO 21:16 } \\
\text { Daytime }\end{array}$ \\
\hline $\begin{array}{l}2009 \\
10 / 19\end{array}$ & $\begin{array}{l}\text { Start: 02:47 } \\
\text { | } \\
\text { End: 12:29 } \\
- \\
-\end{array}$ & $\begin{array}{l}\text { Start: 03:06 } \\
\text { | } \\
\text { End: 12:16 } \\
- \\
-\end{array}$ & $\begin{array}{l}\text { Start: 02:20 } \\
\text { | } \\
\text { End: 12:10 } \\
- \\
-\end{array}$ & $\begin{array}{l}03: 32 \\
07: 33 \\
10: 31 \\
- \\
-\end{array}$ & $\begin{array}{l}X \\
X \\
X \\
- \\
-\end{array}$ & $\begin{array}{l}X \\
X \\
- \\
- \\
-\end{array}$ & $\begin{array}{l}\text { TF028 } \\
- \\
- \\
- \\
-\end{array}$ & $\begin{array}{l}- \\
- \\
- \\
- \\
-\end{array}$ & $\begin{array}{l}- \\
- \\
- \\
\text { Start: } 15: 30 \\
\text { End: 00:15 }\end{array}$ & $\begin{array}{l}\text { MIPAS } \\
50 \mathrm{~km}, 06: 11 \\
\text { Windy } \\
\text { all night }\end{array}$ \\
\hline $\begin{array}{l}2009 \\
10 / 20\end{array}$ & $\begin{array}{l}\text { Start: 05:00 } \\
\mid \\
\mid \\
\text { End: } 12: 26 \\
- \\
-\end{array}$ & $\begin{array}{l}\text { Start: 04:58 } \\
\mid \\
\mid \\
\text { End: } 12: 30 \\
- \\
-\end{array}$ & $\begin{array}{l}\text { Start: 02:16 } \\
\mid \\
\mid \\
\text { End: } 12: 28 \\
- \\
-\end{array}$ & $\begin{array}{l}05: 11 \\
05: 26 \\
08: 11 \\
10: 49 \\
- \\
20: 50\end{array}$ & $\begin{array}{l}\mathrm{X} \\
- \\
\mathrm{X} \\
\mathrm{X} \\
- \\
\mathrm{X}\end{array}$ & $\begin{array}{l}- \\
X \\
- \\
X \\
- \\
-\end{array}$ & $\begin{array}{l}\text { TF029 } \\
- \\
\text { TF031 } \\
- \\
- \\
\text { TM062* }\end{array}$ & $\begin{array}{l}- \\
\text { TF030 } \\
- \\
- \\
- \\
-\end{array}$ & $\begin{array}{l}- \\
- \\
- \\
\text { Start: } 15: 15 \\
\text { End: } 00: 15\end{array}$ & $\begin{array}{l}\text { Cloudy early, } \\
\text { clear after } \\
\text { TES-SO 21:04 } \\
\text { Daytime }\end{array}$ \\
\hline
\end{tabular}

* 10/20 at 20:50 UT: ECC only (no CFH).

throughout the 2-week-long campaign. As there were many more radiosonde launches during the campaign, corrected Vaisala RS92 profiles, as described above (Miloshevich et al., 2009), were also used to link the various datasets together for altitudes between the ground and $18 \mathrm{~km}$. In the remainder of this paper, comparisons will therefore be shown primarily with $\mathrm{CFH}$ if available, then with the corrected radiosonde profiles (referred to as "corrected RS92" for brevity).

Since MOHAVE-2009 was initially motivated by the validation of the water vapor lidars, the campaign spanned over 15 days centered on the October 2009 New Moon period and the balloons were primarily launched during nighttime. A few launches were performed during daytime to accommodate the FTIR measurements and the Aura-TES Special Observations. The lidars operated as long as possible, with emphasis during the three or four nights at New Moon (minimum sky background noise). The microwave measurements were quasi-continuous (day and night) throughout the campaign. A minor Pacific storm prevented most measurements on 13-14 October. Thick high clouds prevented lidar measurements in the first half of the night on 21 October, and most of the night on 27 October, and prevented FTIR mea- surements during the day on 27 October. The rest of the campaign saw nearly cloud-free skies. There was no measurement on the night of 23 October due to well deserved rest for all campaign participants.

Satellite coincidences comprised two close nighttime overpasses for Aura-MLS on 11 and 27 October (a total of 14 coincidences within $500 \mathrm{~km}$ ), two Aura-TES daytime special observations on 18 and 20 October, daily overpasses of Aqua-AIRS (within $200 \mathrm{~km}$ ), four remote overpasses of ACE-FTS, and 18 ENVISAT-MIPAS coincidences within $500 \mathrm{~km}$ (three of them within $100 \mathrm{~km}$ ).

Considering the water vapor measurement uncertainties of instruments that have UTLS capability, and considering the very high water vapor temporal and spatial variability in the troposphere, the MOHAVE-2009 campaign operations and data analysis were planned carefully in order to guarantee meaningful comparisons and interpretations. Two different approaches, based on the altitude range, have been used for the comparisons, especially between lidar and balloonborne measurements. For all altitudes below 13-14 km, only the comparisons from profiles obtained within $100 \mathrm{~km}$ and within $1 \mathrm{~h}$ of each other are shown. Above $21 \mathrm{~km}$, natural 
Table 2b. Summary of MOHAVE-2009 operations (21-28 October).

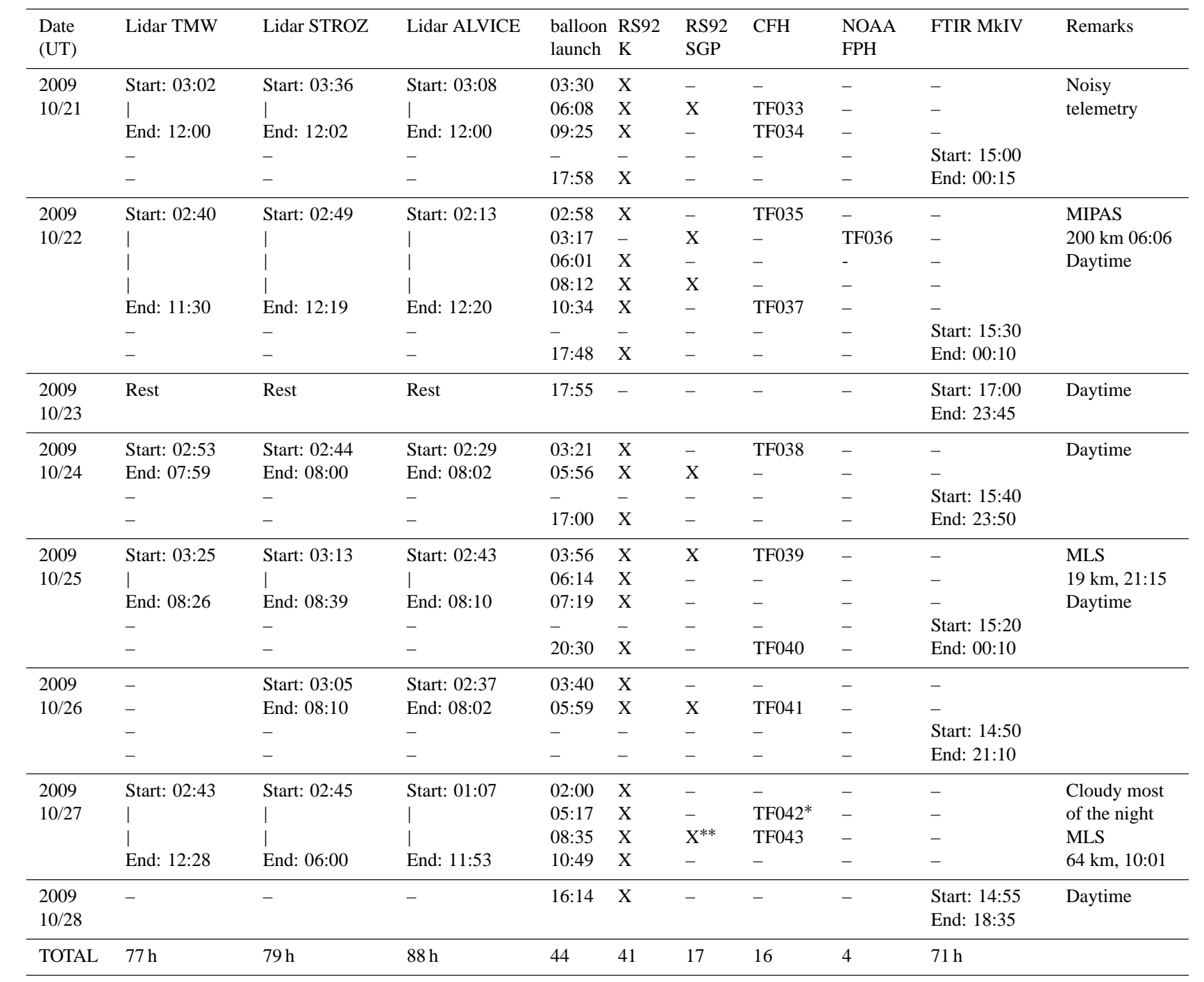

* 10/27 at 05:17 UT: CFH only (no ECC); ${ }^{* *}$ 10/27 at 08:35 UT: sonde launched but data corrupted (no results).

variability is greatly reduced and wider time and horizontal windows ( $250 \mathrm{~km}$ and 6 to $12 \mathrm{~h}$ ) were chosen to increase statistical significance. In the UTLS (14-21 km) either approach was used depending on the application.

\subsection{Modeling in support of the measurements}

In order to optimize the timing of the balloon launches and lidar running times, the outputs from a high resolution Potential Vorticity (PV) advection model were provided to the MOHAVE-2009 participants. The Modélisation Isentrope du transport Mésoechelle de l'Ozone Stratosphérique par Advection (MIMOSA) high-resolution PV advection model was developed in the frame of the European Union project Meridional Transport of Ozone in the Lower Stratosphere (METRO), which was part of Third European
Stratospheric Experiment on Ozone (THESEO) $2000 \mathrm{cam}-$ paign (Hauchecorne et al., 2002). In forecast mode, the ECMWF forecasted winds are input to the model. The resulting PV fields are interpolated onto the model's orthogonal grid. Then the PV of each grid point is advected using the ECMWF winds, and re-gridded. The quantity advected and then output by the model is not the true dynamical PV but a quasi-passive PV which correlates well with the concentration of ozone in the LS. The basic assumption is that lower stratospheric ozone mixing ratio and PV are very well correlated on an isentropic surface and the location of ozone filaments can be visualized using PV as a quasi-passive tracer. Ozone concentration in the LS is a good indicator of the origin of the air masses, hence making MIMOSA a useful tool for the study of transport near the 

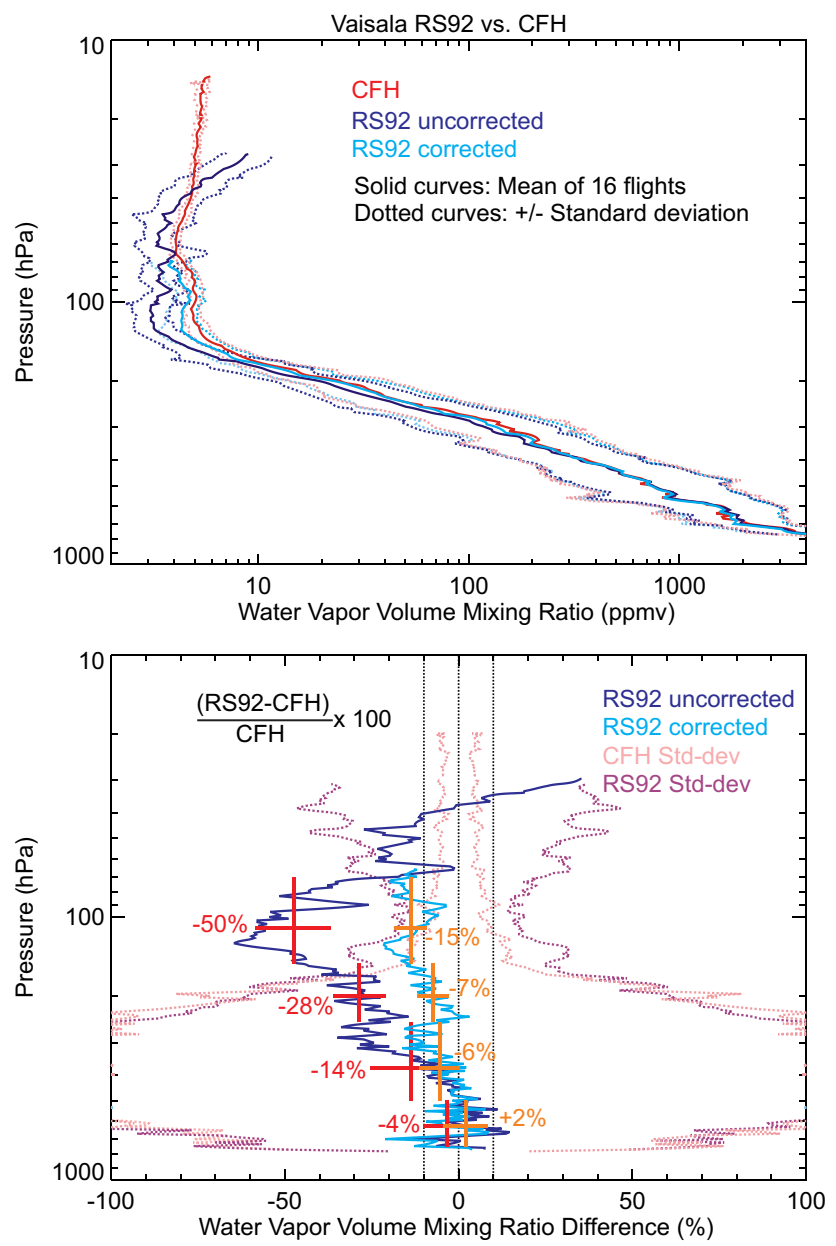

Fig. 1. Campaign-mean mixing ratio profiles (top) measured simultaneously by RS92 and CFH, and their difference (bottom). Both corrected and uncorrected RS92 are compared to CFH. The thick, red (uncorrected) and orange (corrected) vertical and horizontal bars indicate layer-averaged differences and standard deviations respectively.

tropopause. The MIMOSA PV fields were produced daily at Service d'Aéronomie du CNRS and downloaded in nearreal-time to JPL for use by all MOHAVE-2009 participants. MIMOSA allowed, for example, the early forecast and identification of a deep stratospheric intrusion during the night of 20 October, which triggered the decision to launch multiple Frost-Point hygrometers and radiosondes on the same night and run the lidars for an extended period of time. Another version of the model runs in analysis mode, i.e., using the ECMWF analyzed winds instead of the forecasted winds. Some results from the analysis mode will be shown in Sect. 4.2. Additional details on the MIMOSA model are given in (Hauchecorne et al., 2002).
RS92 corrected vs. RS92 uncorrected
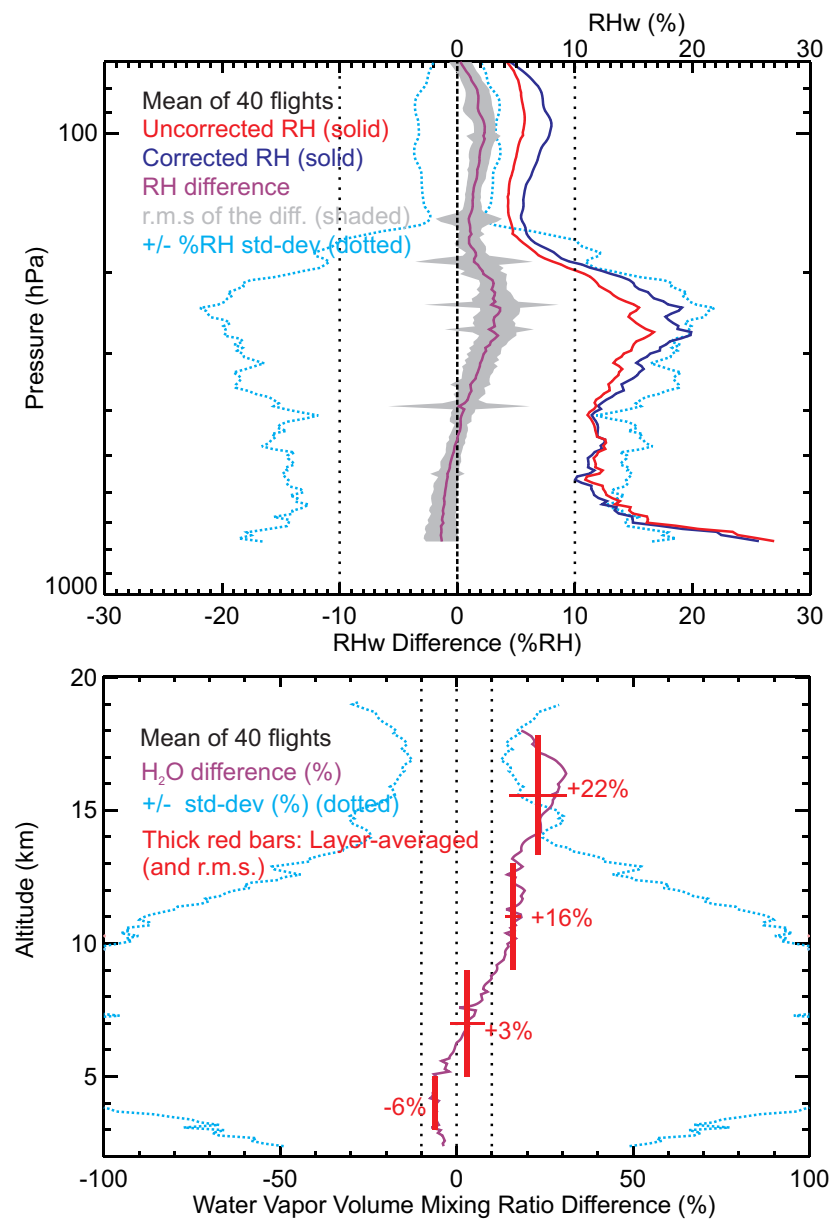

Fig. 2. Campaign-mean RH with respect to water (top) and water vapor mixing ratio (bottom) difference (purple curves) between the corrected (as described by Miloshevich et al., 2009) and uncorrected RS92 profiles. On the top panel, the uncorrected and corrected RHw profiles are over-plotted using a red and blue solid curve (\% RH scale on top-right $\mathrm{x}$-axis).

\section{Results}

\subsection{Sonde intercomparisons}

As mentioned above, the focus of the campaign was on the validation of the lidar measurements in the UTLS. However, the presence of multiple balloon-borne techniques allowed the investigation of the temperature, pressure and humidity biases between the sensors mounted on the same balloon payloads. Thorough comparisons of data re-analyzed several times provided a confirmation of several expected features as well as the identification of new ones. For example, the RS92 humidity measurements showed, as expected, a large dry bias in the cold upper troposphere. Additionally, the RH measurements from the iMet-1 radiosonde were found unreliable. They will not be considered, shown, or 

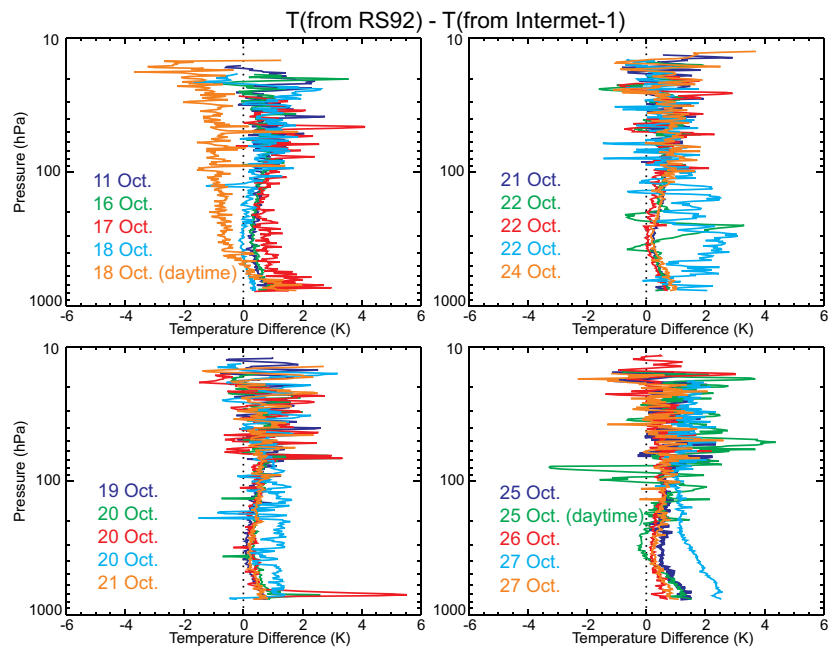

Fig. 3. Measured temperature difference between the Vaisala RS92 and the InterMet iMet-1 radiosondes when both radiosonde types were mounted on the same payload ( 20 balloon flights). All flights at nighttime unless otherwise specified.

discussed in the present paper. Finally, the Vaisala and InterMet radiosonde measurements showed a temperature bias of roughly 0.2 to $1 \mathrm{~K}$, the InterMet measurement being colder. The radiosonde measurements also showed pressure differences which are investigated by Hurst et al. (2011b). It will be shown that these differences have a small impact on the Frost-Point Hygrometer measurements.

Figure 1 (top) shows the mean water vapor profiles (and their standard deviations) measured by the RS92 and CFH on all flights that had both instruments on the same payload. Though they could possibly have been merged with the CFH, the NOAA-FPH measurements comprise an independent data set and were not included here due to the limited number of measurements, but typically yield the same results as the CFH. Both the uncorrected and corrected RS92 profiles are shown. As was observed in previous campaigns, the uncorrected RS92 measurements show a large negative (dry) bias in the upper troposphere. Figure 1 (bottom) shows the corresponding percentage differences (CFH taken as the reference). The mean dry bias in the uncorrected RS92 measurements reaches $-50 \%$ in the UTLS. Using results from past campaigns, Miloshevich et al. (2006, 2009) provided time-lag and empirical corrections that led to a better capture of the fine RH vertical structures in the upper troposphere. The empirical correction also leads to slightly drier profiles in the lower troposphere and significantly wetter profiles in the upper troposphere. The corrected RS92 mean mixing ratio profile remains within $\pm 10 \%$ of that measured by the $\mathrm{CFH}$ throughout the troposphere (up to about $150 \mathrm{hPa}$ ). The mean effect of the radiosonde correction on $\mathrm{RH}$ and water vapor mixing ratio is plotted in Fig. 2. The absolute effect on RH maximizes in the upper troposphere $(4 \% \mathrm{RH})$, while

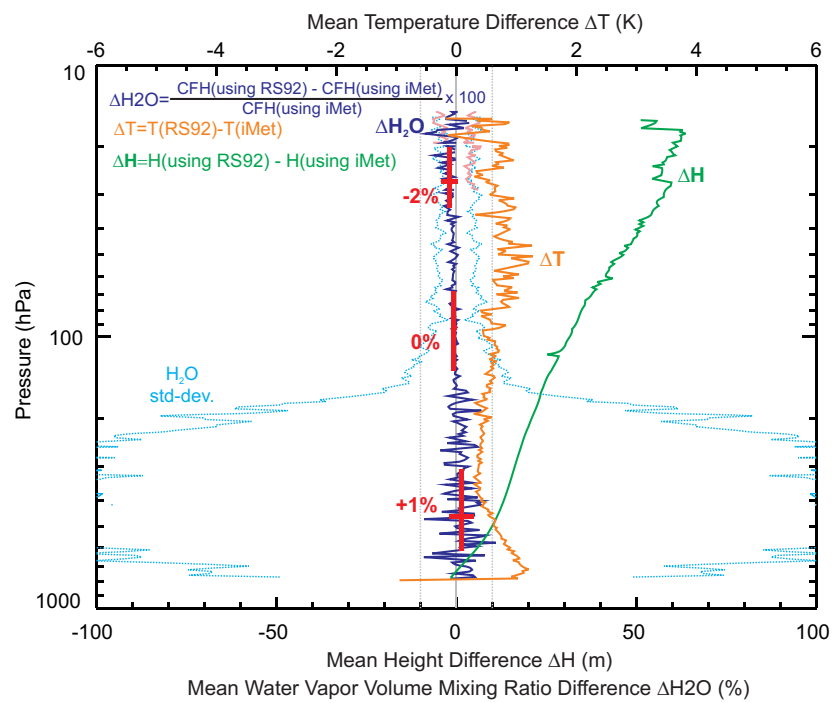

Fig. 4. Campaign-mean difference resulting from the systematic biases between RS92 and iMet-1 radiosonde data. Orange: mean radiosonde temperature difference; green: mean geopotential height difference; dark blue: $\mathrm{CFH}$-derived water vapor mixing ratio mean difference. The thick red horizontal and vertical bars denote layeraveraged differences and associated standard deviations. Only the 14 most consistent flights (out of 16) were used to compute these means.

the effect on water vapor mixing ratio maximizes just above the tropopause ( $\sim 20 \%$ or $1 \mathrm{ppmv}$ at $15 \mathrm{~km})$. Figure 2 also highlights the mean vertical structure of $\mathrm{RH}$ and water vapor variability (cyan dotted curves), with an abrupt change near $200 \mathrm{hPa}$ and $10 \mathrm{~km}$ where it decreases to low stratospheric values. This change is even more abrupt on individual profiles and occurs at altitudes between $9 \mathrm{~km}$ and $12 \mathrm{~km}$. For additional details about the RS92 corrections and comparison to the frost-point hygrometers including $\mathrm{CFH}$ and NOAAFPH, see Hurst et al. (2011b) and Whiteman et al. (2011).

Figure 3 shows the measured temperature bias for every balloon flight whose payload included both types of radiosonde (Vaisala and InterMet). The biases observed on 18 October (daytime flight) and 27 October (third flight of the night, cyan curve) appear atypical due to operational issues. The first profile of 22 October (green curve) shows a wavy structure of large amplitude at around $200-300 \mathrm{hPa}$ resulting from the loss of RS92 telemetry data over an extended period of the flight. For all other flights, a general pattern can be recognized, consisting of a $1 \mathrm{~K}$ cold bias for iMet- 1 at the ground decreasing to $0.2 \mathrm{~K}$ in the middle troposphere $(400 \mathrm{hPa})$, then increasing again to $1 \mathrm{~K}$ in the upper troposphere and stratosphere. Pressure differences between the InterMet and Vaisala sensors were also observed during MOHAVE-2009. A thorough investigation of these temperature and pressure differences between the two radiosonde sensors is presented by Hurst et al. (2011b). Figure 4 shows the campaign-averaged temperature bias between the two 

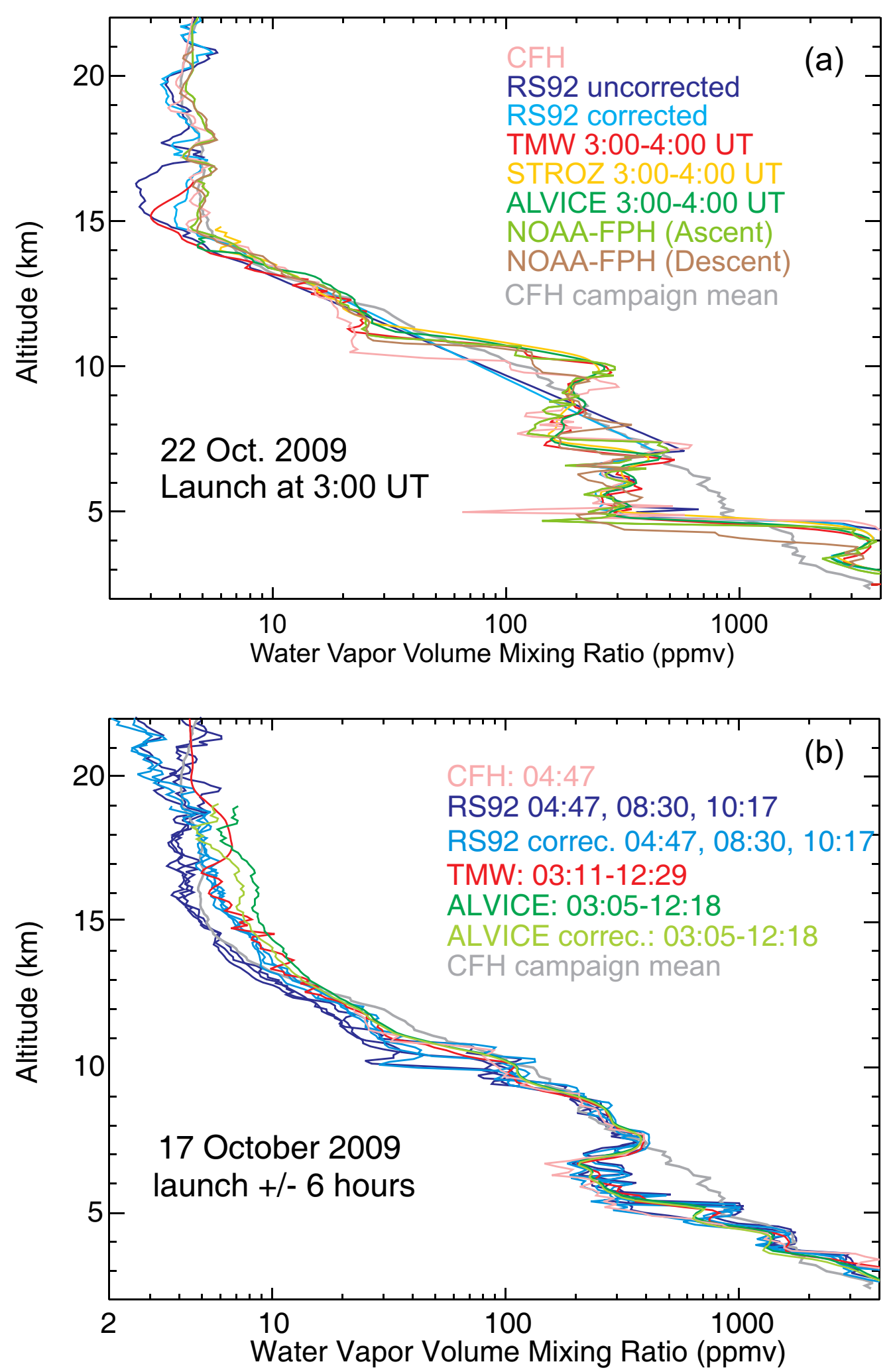

Fig. 5a and b. Balloon-borne and lidar water vapor profiles measured on various campaign nights (with various coincidence criteria applying). Top (a): simultaneous, lidar integrated for one hour, i.e., from launch time to one-hour after launch. Bottom (b): lidar integrated for several hours with a $\pm 6 \mathrm{~h}$ coincidence criterion with balloon measurements. See text for details. 

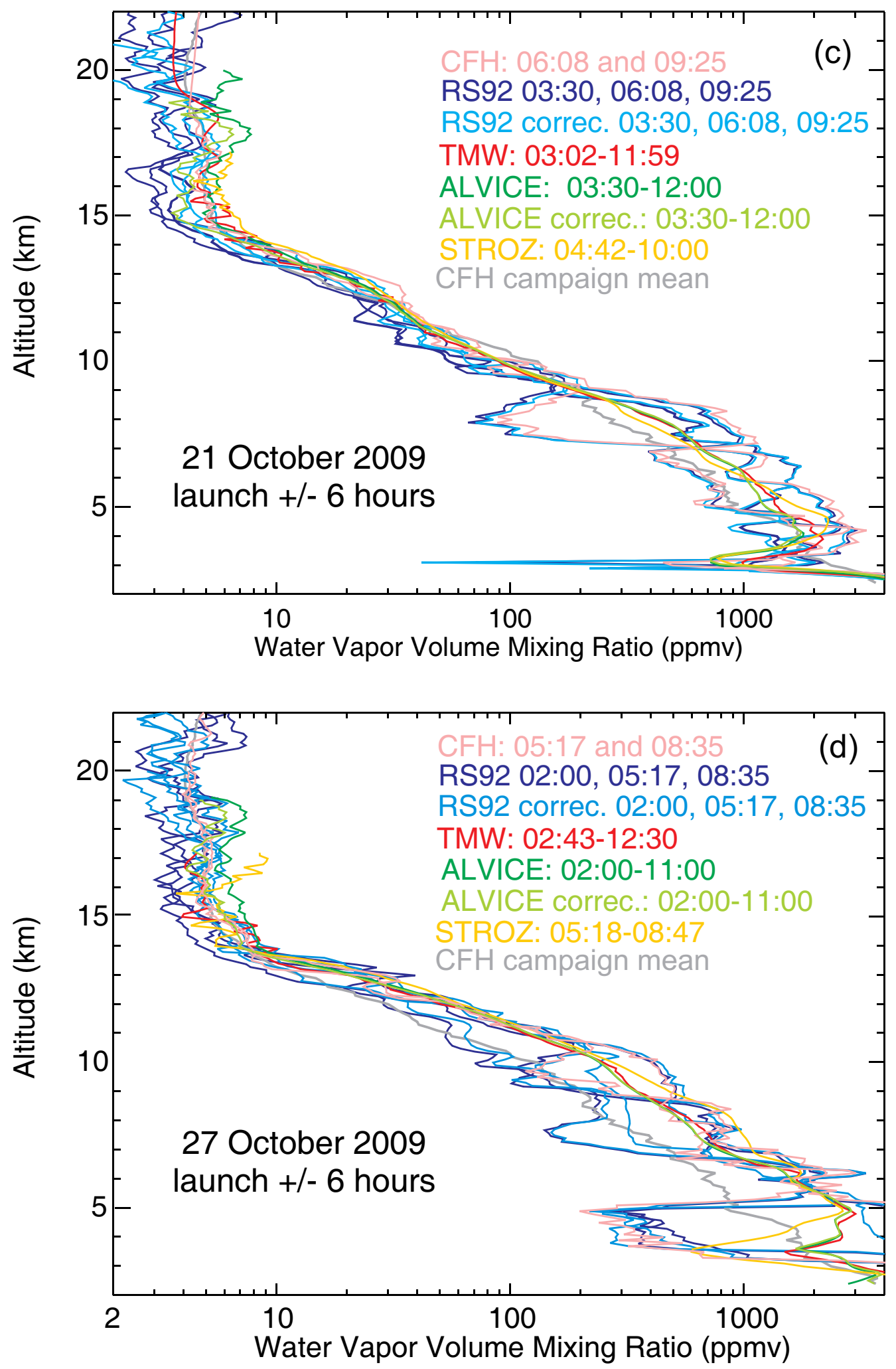

Fig. 5c and d. Balloon-borne and lidar water vapor profiles measured on various campaign nights (with various coincidence criteria applying). Lidar integrated for several hours with a $\pm 6 \mathrm{~h}$ coincidence criterion with balloon measurements. See text for details. 
radiosonde types for the 14 most consistent flights of the campaign (orange curve, top x-axis in Kelvin), as well as the resulting geopotential height error calculated from the hypsometric equation (green curve, bottom x-axis in meters). Note that because it is calculated directly using the pressure and temperature readings of each type of sonde and plotted as a function of pressure, the mean height difference observed in Fig. 4 is a direct consequence of the temperature bias between the two radiosonde sensors, regardless of any possible bias in the pressure readings between the two radiosonde sensors. Interestingly, Hurst et al. (2011b), who first mapped the sonde profiles based on a common time reference (launch detection time), then compiled the height difference between the two sensors as a function of height, show that the pressure bias between the two radiosonde sensors has a significant impact above $20 \mathrm{~km}$ (see their Figs. 6 and 7). The bias between the two radiosonde types indeed impacts the derivation of water vapor mixing ratio by the Frost-point hygrometers (NOAA-FPH and $\mathrm{CFH}$ ). The resulting water vapor mixing ratios derived by the $\mathrm{CFH}$ are slightly higher (less than $1 \%$, statistically not significant) in the lower troposphere, and slightly lower ( $-2 \%$, statistically significant) in the lower stratosphere if RS92 pressure is used instead of iMet-1 pressure (dark blue curve, bottom x-axis in percent on Fig. 4). Below $20 \mathrm{~km}$, these differences remain well below the reported total uncertainties of the Frost-Point instruments (typically 5-10\%). As shown by Hurst et al. (2011b) the uncertainty in the pressure measurements mostly impacts the upper part of the profiles (above $20 \mathrm{~km}$ ) where small absolute biases (such as $0.1 \mathrm{hPa}$ ) produce large relative biases in the mid-stratosphere.

\subsection{Lidars}

Figure 5 shows four examples of water vapor mixing ratio profiles measured simultaneously by lidar and the balloonborne instruments on different nights of the campaign. These four particular cases were specifically selected to illustrate the importance of the spatio-temporal match of the various datasets. Figure 5a shows profiles strictly coinciding in time, with lidar measurements integrated for one hour starting at launch time. The other three panels (b, c, d) show comparisons with a more relaxed time coincidence criterion $( \pm 6 \mathrm{~h})$, and with longer and more variable lidar integration times (typically 4 to $10 \mathrm{~h}$ ). On 22 October (a), all lidar profiles and the NOAA-FPH ascent profile agree very well up to $14 \mathrm{~km}$. The 1-h-integrated lidar measurements become noisy above this altitude. This example shows also a malfunction of the RS92 radiosonde and the resulting loss of information between 7 and $12 \mathrm{~km}$. As a result the CFH profile computed using the RS92 pressure shows a significant disagreement with the lidar and NOAA-FPH ascent profiles. Outside this $7-12 \mathrm{~km}$ layer, all profiles are in very good agreement. One exception is the dry layer between 3.5 and $4.5 \mathrm{~km}$ measured by the NOAA-FPH during balloon descent, likely a result of

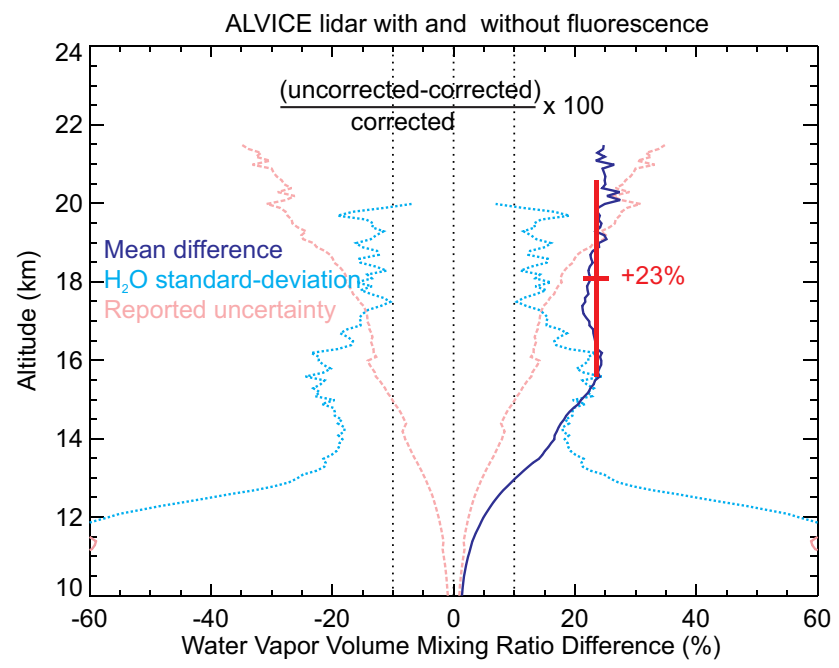

Fig. 6. Mixing ratio difference between the fluorescence-corrected and uncorrected ALVICE lidar profiles. The thick red vertical and horizontal lines indicate the $15-20 \mathrm{~km}$ layer-averaged difference and standard deviation respectively. The measurements standard deviation and uncertainty are over-plotted in dotted cyan and dashed pink respectively.

the balloon drift and loss of simultaneity and co-location. On 17 October (b), there is little variability throughout the night, and again all profiles agree well, though the coincidence criterion was relaxed. On 21 October (c), water vapor varies significantly in the lower and mid-troposphere between the first half (03:30 UT) and the second half (09:30 UT) of the night (see CFH and RS92 profiles). Interestingly, the lidar measurements integrated all night resulted in a smooth profile corresponding to the average of the balloon-borne profiles measured at the beginning and the end of the night. On 27 October (d), high variability combined with varying lidar integration windows result in significant differences between lidar and balloon, but also between lidar and lidar (e.g., STROZ and the other two lidars at 4-5 km). These four cases illustrate well how cautious one must be when interpreting tropospheric water vapor measurements differences.

Further inspection of Fig. 5 shows that the lidar profiles agree well up to about $10-12 \mathrm{~km}$, then the ALVICE lidar profiles show a wet bias compared to CFH and the JPL lidar TMW. The wet bias was identified early in the campaign as the result of fluorescence induced by the strong Rayleigh returns at the entrance of both the STROZ and ALVICE lidar receivers, thus contaminating the weak Raman signal of the water vapor far-range channel (McGee et al., 2011) and (Whiteman et al., 2011). For ALVICE it is believed to have been caused by organic residues deposited on the telescope primary mirror (insects burned by the laser beam). For the STROZ system, it originated in the receiver optics. In this latter case, the issue was mitigated during the campaign by applying a blocking filter. The profiles contaminated by 


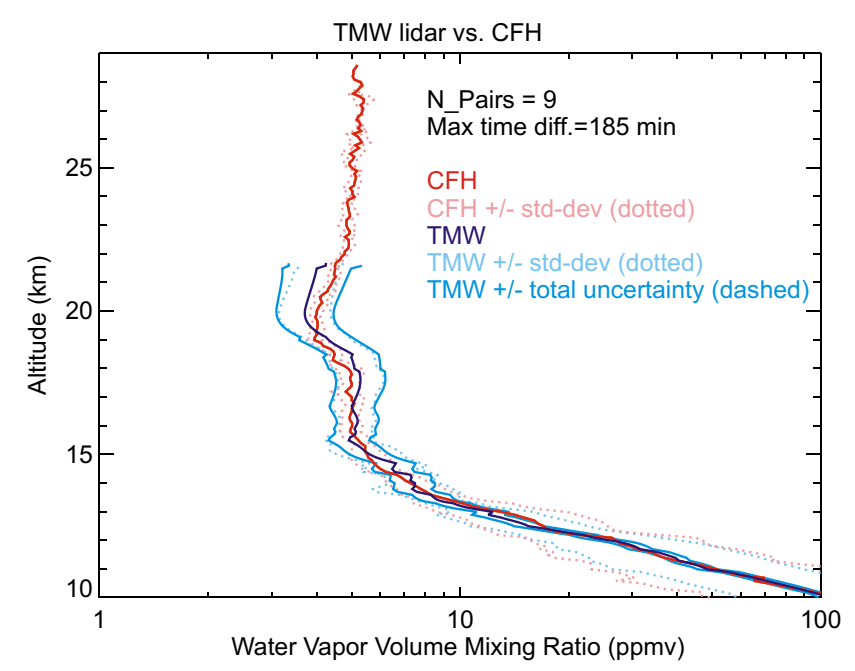

Fig. 7. Campaign-mean water vapor mixing ratio profiles in the UTLS obtained from the coincident 9 CFH launches and 9 TMW lidar nights ( $\pm 6 \mathrm{~h}$ time coincidence).

fluorescence were removed from the database and are not shown here. The ALVICE profiles contaminated by fluorescence are shown on Fig. 5. An empirically corrected version of these profiles was released together with the uncorrected profiles (Whiteman et al., 2011). The magnitude of the contamination by fluorescence calculated from these two versions is shown on Fig. 6. On this plot, the contamination is negligible below $10 \mathrm{~km}$, then increases rapidly between $10 \mathrm{~km}$ and $15 \mathrm{~km}$, and remains nearly constant $(\sim 20 \%)$, typically expressing the physical nature of fluorescence, i.e., undesired lidar signal roughly proportional to atmospheric density adding to the water vapor Raman signal and equivalent to a nearly constant mixing ratio moist offset. The empirical correction makes use of an external source of measurements, in this case $\mathrm{CFH}$, which makes the fluorescence correction similar in principle to a second calibration, this time in the UTLS (Whiteman et al., 2011). Despite the unfortunate fluorescence contamination of the ALVICE and STROZ lidar data, the results from the non-contaminated TMW lidar instrument demonstrate the potential of the Raman lidar technique for measurement of water vapor in the UTLS. Figure 7 shows for example the campaign-mean water vapor mixing ratio profiles obtained above $10 \mathrm{~km}$ by the $\mathrm{CFH}$ (mean of nine launches) and by the JPL lidar (mean of nine nights coinciding with the CFH launches). The lidar profiles integrated all night can reach an altitude of $20 \mathrm{~km}$ with a mean bias with CFH not exceeding 0.5 ppmv $(10 \%)$. The mean lidar precision in these conditions is about $1 \mathrm{ppm}(20 \%)$.

Another demonstration of the capability of the JPL water vapor Raman lidar at TMF is presented on Fig. 8. This figure shows a three-dimensional view of typical transport processes near the tropopause. The JPL tropospheric ozone differential absorption and water vapor Raman lidars, supported by the high-resolution PV advection model MIMOSA, captured the signatures of air masses of very different origins: low PV, low ozone and high water vapor content measured in air masses originating in the tropical upper troposphere (early night at $12-13 \mathrm{~km}$ and $355 \mathrm{~K}$ as well as late night at $10 \mathrm{~km}$ and $330 \mathrm{~K}$ ), and high PV, high ozone and low water content measured in air masses originating in the highlatitude, lowermost stratosphere (late night at $12-13 \mathrm{~km}$ and $355 \mathrm{~K}$ as well as early night at $10 \mathrm{~km}$ and $330 \mathrm{~K}$ ). A complete description of the simultaneous ozone and water vapor lidar observations during MOHAVE-2009, and in particular the identification of a deep stratospheric intrusion on 20 October, is presented in Leblanc et al. (2011b). Note that besides the instrumental optimization, the extended range of the three lidars observed during the campaign is facilitated by the high elevation of the observing site $(2300 \mathrm{~m})$.

\subsection{Tropospheric profiles from passive remote sensing}

The ground-based FTIR MkIV can produce daytime water vapor mixing ratio profiles with about 3 to 4 independent pieces of information in the troposphere (Schneider et al., 2010). These low resolution profiles were compared to balloon-borne measurements (mainly Vaisala RS92 radiosondes) and coincident satellite measurements. Figure 9 shows an example of a daytime profile measured during the 18 October 2009 Aura-TES Special Observation over TMF. Once again, the uncorrected RS92 profile appears much too dry above $11 \mathrm{~km}$ compared to CFH. All passive remote sensing instruments (FTIR, TES and AIRS) agree well with the CFH below $11 \mathrm{~km}$. Despite the fact that no averaging kernel was applied to the higher resolution $\mathrm{CFH}$ and radiosonde profiles, this figure shows that the satellite measurements are clearly able to capture both the dry anomaly (with respect to the campaign mean) in the lower troposphere and the wet anomaly just above. The FTIR instrument captured only the wet upper troposphere. However, a comparison of the campaign-mean profiles measured simultaneously by radiosonde and FTIR shows very good agreement throughout the troposphere (Fig. 10) with no apparent systematic biases at altitudes between 3 and $12 \mathrm{~km}$.

\subsection{Stratospheric profiles}

Stratospheric measurements of water vapor during MOHAVE-2009 were available from the two groundbased microwave radiometers (WVMS and MIAWARA-C) and from the satellite instruments Aura-MLS, ENVISATMIPAS and ACE-FTS. Figure 11 shows a comparison of MLS version 2 and 3 with CFH for the four close coincidences found during MOHAVE-2009. The CFH profile is presented both on its native high vertical resolution grid (orange) and interpolated onto MLS's pressure grid (red). The MLS profiles remain in close agreement $(5-10 \%)$ with $\mathrm{CFH}$ above $100 \mathrm{hPa}$. A systematic and singular (20-40\%) 


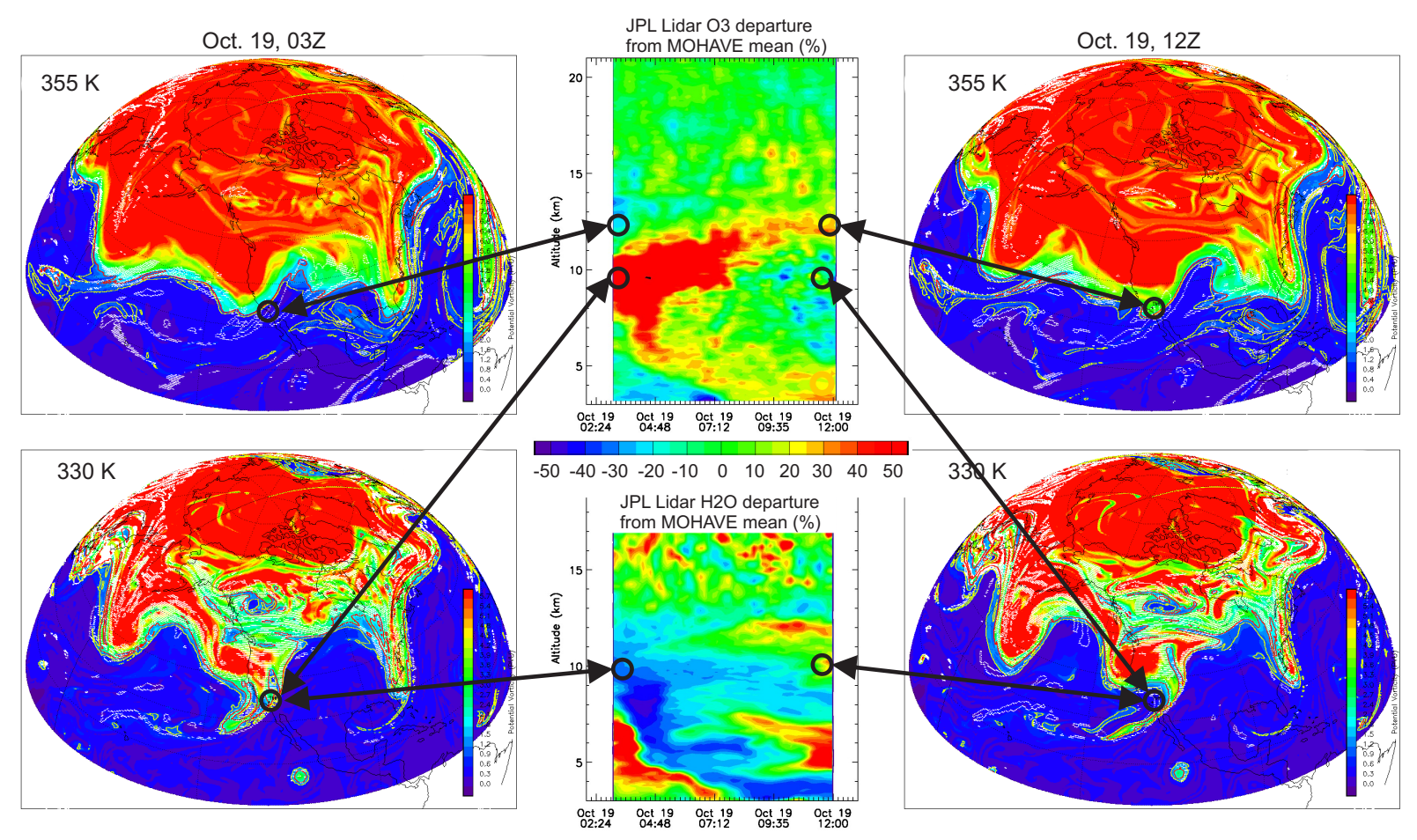

Fig. 8. A three-dimensional view of transport processes identified during MOHAVE-2009 by the JPL/TMF ozone differential absorption lidar and water vapor Raman lidar, and supported by the high-resolution PV advection model MIMOSA. The location of TMF, as well as the main atmospheric events identified by lidar and the model are denoted by open circles. See text for details.

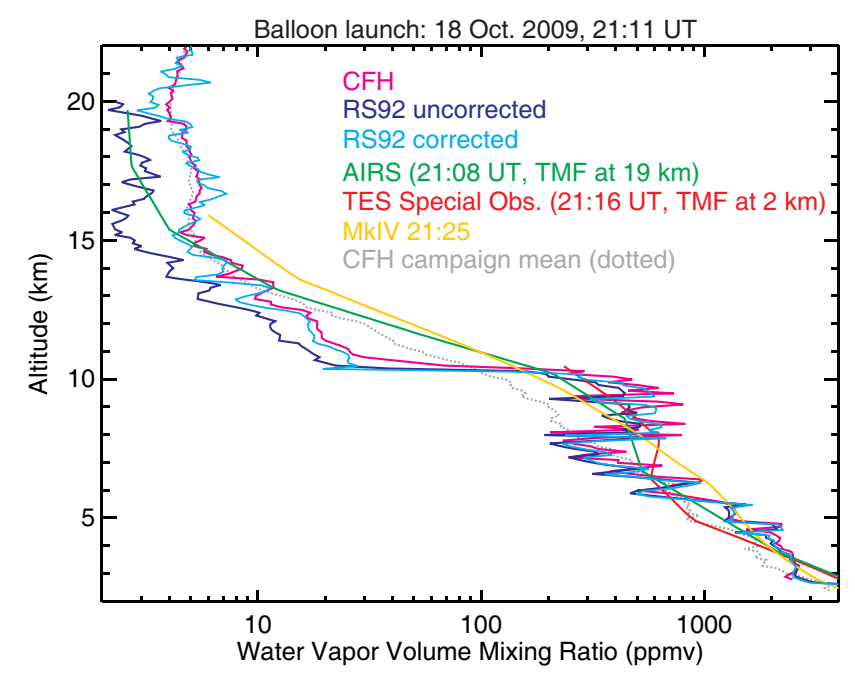

Fig. 9. Tropospheric water vapor mixing ratio profiles measured simultaneously by in-situ and passive remote sensing instruments and techniques on 18 October 2009 (daytime launch).

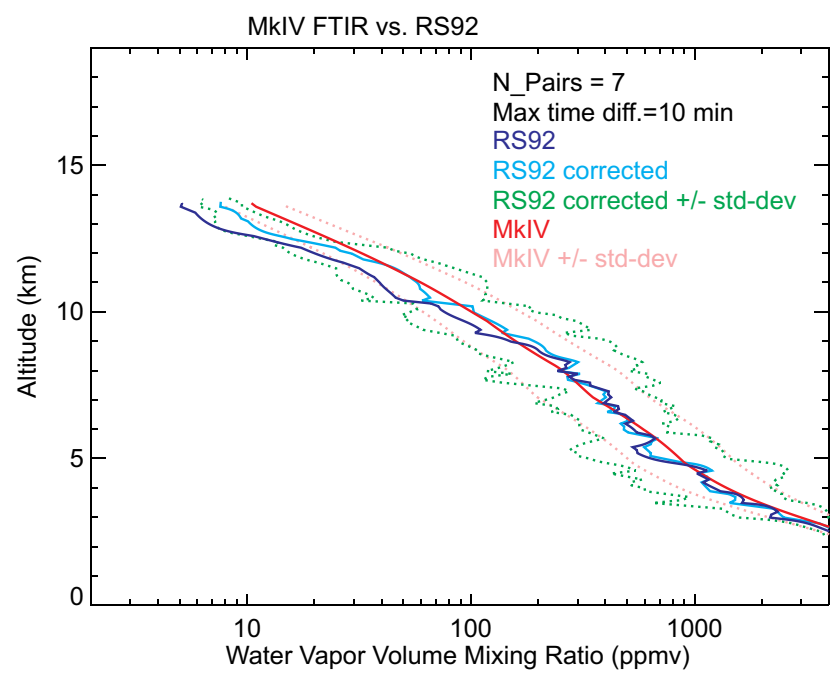

Fig. 10. Campaign-mean water vapor mixing ratio profiles, and standard deviations, measured simultaneously by the ground-based FTIR MkIV and the Vaisala RS92 PTU radiosondes (7 coincidences). 

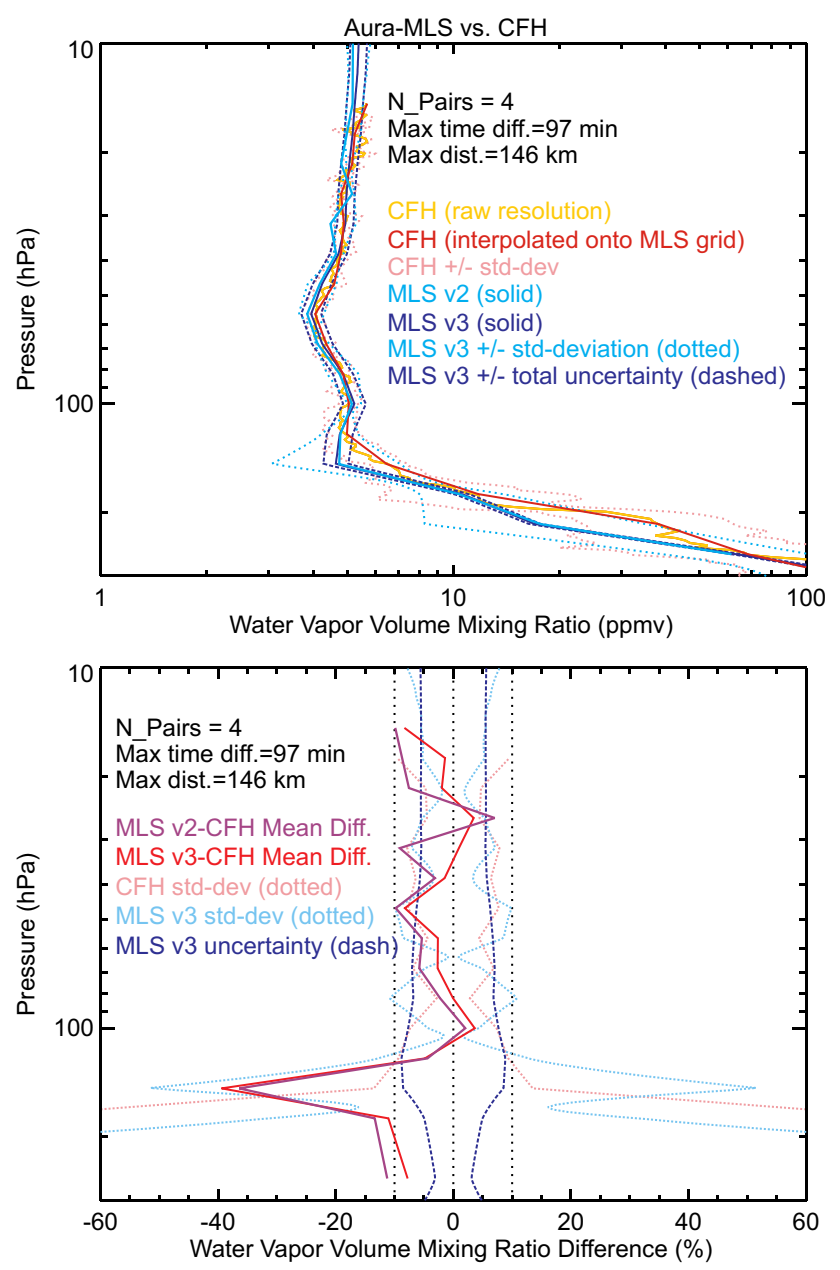

Fig. 11. Water vapor mixing ratio profiles measured simultaneously by Aura-MLS v2, v3, and CFH during MOHAVE-2009 (top), and their relative difference (bottom).

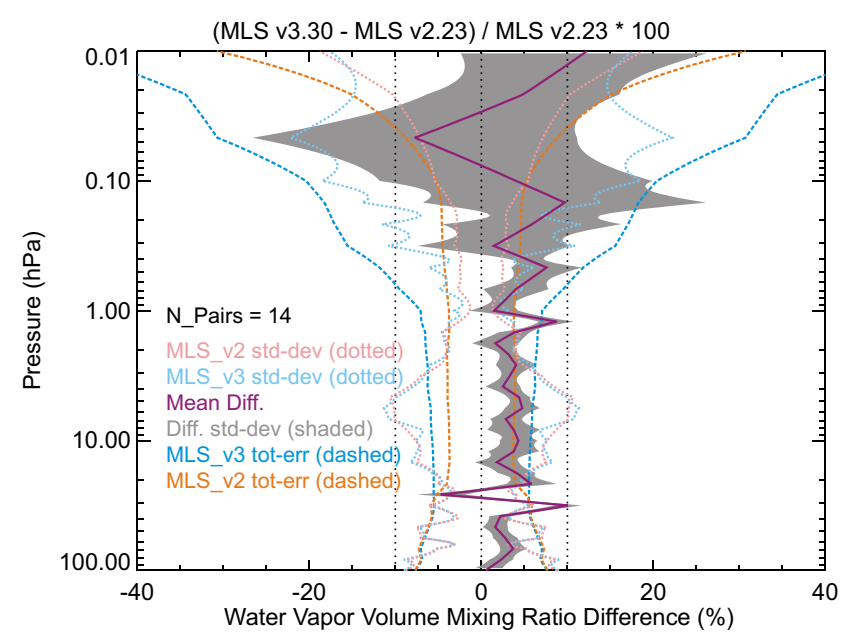

Fig. 12. Water vapor mixing ratio differences (\%) between AuraMLS v2.23 and Aura-MLS v3.3, during MOHAVE-2009.
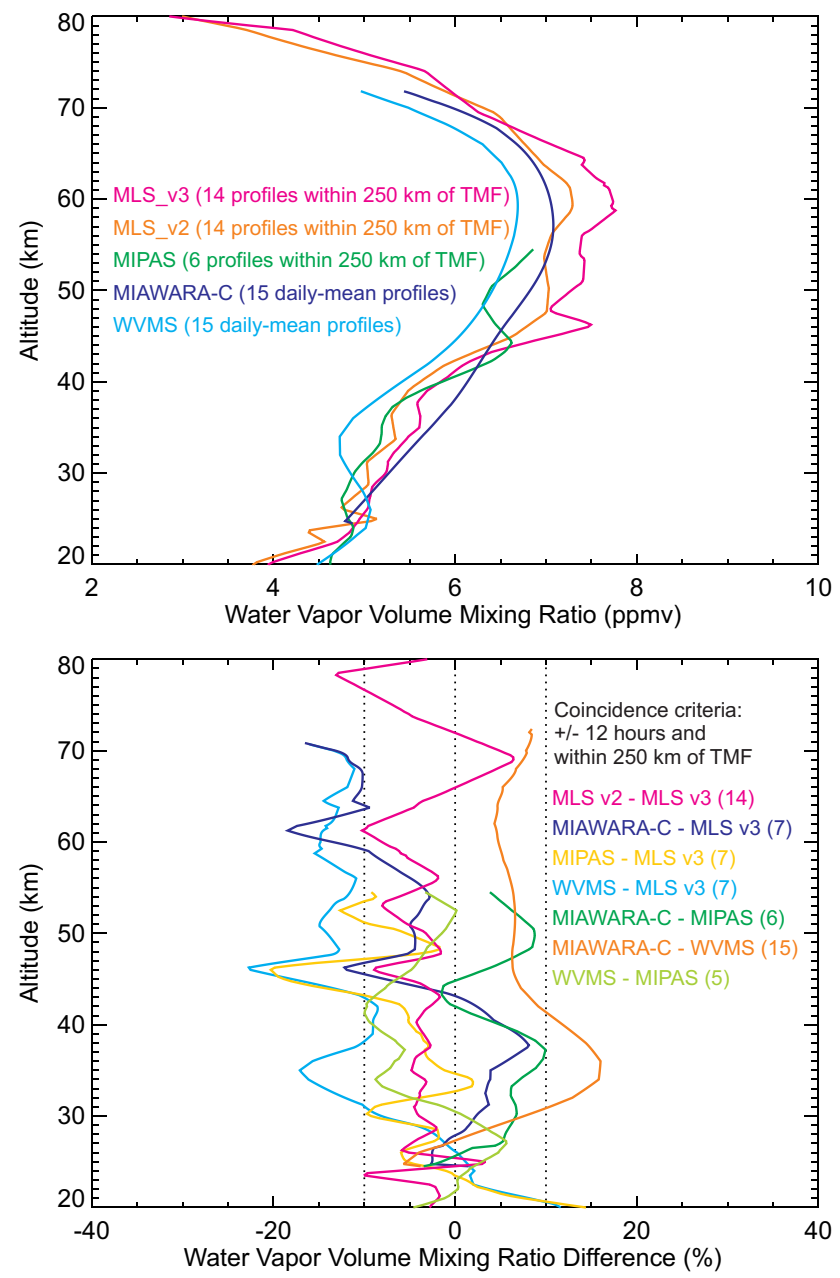

Fig. 13. Mean water vapor mixing ratio profiles (top) measured during MOHAVE-2009 by the stratospheric sounders (MLS, MIAWARA-C, WVMS, and MIPAS) and mean differences (\%) between them (bottom). The numbers in parenthesis indicate the number of coincidences.

dry bias is observed on the MLS profiles at $120 \mathrm{hPa}$ due to the sudden and large increase of water vapor mixing ratio just below the tropopause which cannot be handled properly by the satellite instrument's averaging kernels. The differences between MLS version 2 and version 3 are plotted on Fig. 12. Version 3 is, on average, $3-4 \%$ wetter than version 2 . A systematic wavy feature in version 2 between 20 and $40 \mathrm{hPa}$ was removed in version 3 leading to a better agreement with $\mathrm{CFH}$. The spread of the differences increases in the mesosphere, version 3 profiles being slightly noisier due to an increase in the vertical resolution (A. Lambert, personal communication, 2011).

Figure 13 shows the mean water vapor profiles (top) and mean differences (bottom) measured by all stratospheric sounders during the campaign. The differences were calculated based on a different number of coincidences depending on the instrument pair considered. All profiles were 


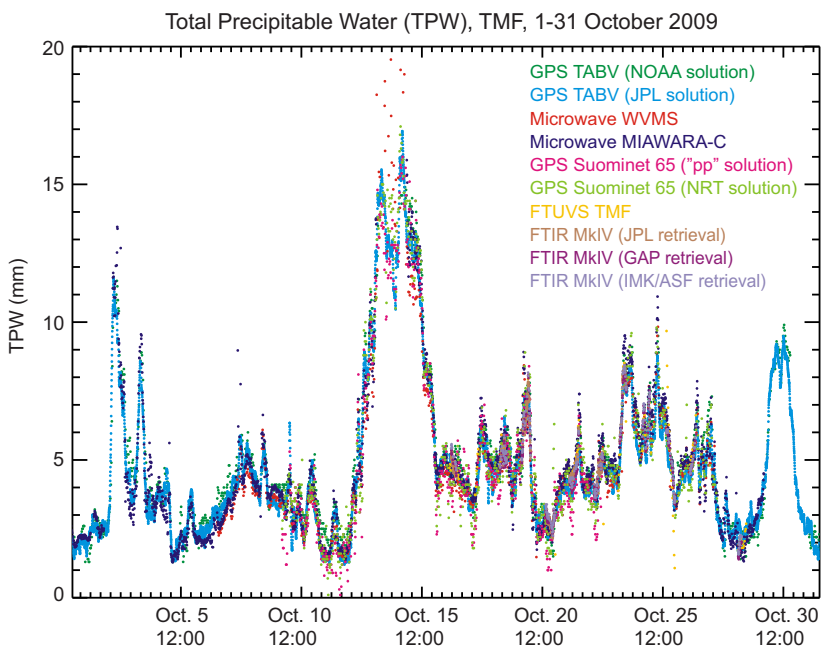

Fig. 14. Time series (1-31 October 2009) of the Total Precipitable Water datasets obtained from the two GPS, two microwave radiometers, and two Fourier Transform Spectrometers deployed at TMF during MOHAVE-2009. Sampling interval varies between 10min and 45-min.

interpolated onto a geometric altitude grid. A relaxed coincidence criterion of $\pm 12 \mathrm{~h}$ and within $250 \mathrm{~km}$ of TMF was chosen in order to maximize the number of coincidences and statistical significance. This led to 14 Aura-MLS overpasses (one per day) over the course of the campaign, 6 overpasses for ENVISAT-MIPAS, and 15 daily-mean profiles for the ground-based microwave radiometers. $4 \mathrm{x}$-daily retrievals for the microwave radiometers were also available. No specific features came out of these higher temporal resolution profiles and only the daily mean profiles are shown here. WVMS is found to be slightly drier than all other instruments: 0-10\% drier than MIPAS, $10 \%$ drier than MIAWARA-C, and 10$15 \%$ drier than Aura-MLS v3. Above $40 \mathrm{~km}$, MLS v3 is wettest while below $40 \mathrm{~km}$, MIAWARA-C is wettest. Both ground-based radiometers are drier than MLS in the mesosphere. Note that the satellite measurements have a finer vertical resolution than the ground-based microwave instruments. However, most biases between instruments remain within the reported uncertainties of one or both instruments being compared.

A more detailed comparison of the MIPAS water vapor profiles to the other instruments as well as comparison of temperature and ozone profiles is given by Stiller et al. (2011). These comparisons hint towards a small positive bias of MIPAS water vapor just above the hygropause and around $45 \mathrm{~km}$, and a pronounced negative bias above $50 \mathrm{~km}$. The latter is well-known and can be explained by the neglect of local thermodynamic disequilibrium effect in the radiative transfer modeling. None of the detected biases is significant in the sense that it exceeds the estimated precision of the instrument.

\subsection{Total Precipitable Water (TPW)}

Total Precipitable Water (TPW) was measured by a number of different instruments and techniques. Only datasets from the ground-based GPS, microwave and FTS instruments will be considered here as they provide the best temporal coverage, i.e., nearly continuous measurements at sampling intervals between 10 and $45 \mathrm{~min}$. TPW (in $\mathrm{mm}$ ) measured by these instruments is plotted against time on Fig. 14. In this figure, data points for the WVMS radiometer (red dots) before 6 October were removed due to a bad amplifier. The first feature immediately apparent is the significant dryness of the site. The 2285-m elevation of TMF and its location in the subtropical branch of the Hadley circulation (desert belt) account for such a climatological dryness. Nevertheless, TMF is close to the mid-latitude storm track and the three TPW maxima ( $10 \mathrm{~mm}$ on 4 and 29 October, and $15 \mathrm{~mm}$ on 14 October) coincide with the passing of early winter storms. The other main feature observed in this figure is the excellent agreement between all datasets. A comparison of all the TPW datasets is shown in Fig. 15 (differences in millimeters in the top panel and percent in the bottom panel). Datasets can be easily identified by their color. Prior to computing the differences, the raw time-series of each dataset was interpolated to a regular temporal grid of 30-min resolution. For each panel of Fig. 15, the symbols indicate the campaign-mean differences between the dataset listed in the upper part of the panel (where the minimum and maximum number of coincidences is listed) and those listed in the lower part. The vertical bars show the spread of these differences. A Gaussian function was fitted to the distribution of the individual differences. The mean values (symbols) correspond to the values where the Gaussian fits maximize, and the spread (vertical bars) corresponds to the fits' full-width at half-maximum. As anticipated from the timeseries, the differences do not exceed $1 \mathrm{~mm}$ or $10 \%$. There is a 5-6\% difference between the NOAA and JPL solutions retrieved from the same GPS (TABV). The daily solution of the SuomiNet GPS (SA-65-pp) appears slightly noisier and $10 \%$ drier than the hourly solution (SA65-nrt). TPW retrieved from the WVMS also shows a slightly larger dry bias with the other datasets but this bias remains below $10 \%(0.5 \mathrm{~mm})$. All the other datasets remain within $5 \%(0.3 \mathrm{~mm})$ of each other. The agreement between various TPW products during MOHAVE-2009 shows a slight improvement over previous intercomparisons (Revercombe et al., 2003). The robustness of the TPW retrievals also supports the justification of their use in constraining and validating profiling measurements (Turner and Goldsmith, 1999; Whiteman et al., 2006).

\section{Summary and conclusion}

The MOHAVE-2009 campaign took place at the JPL Table Mountain Facility in California $\left(34.4^{\circ} \mathrm{N}\right)$ on 

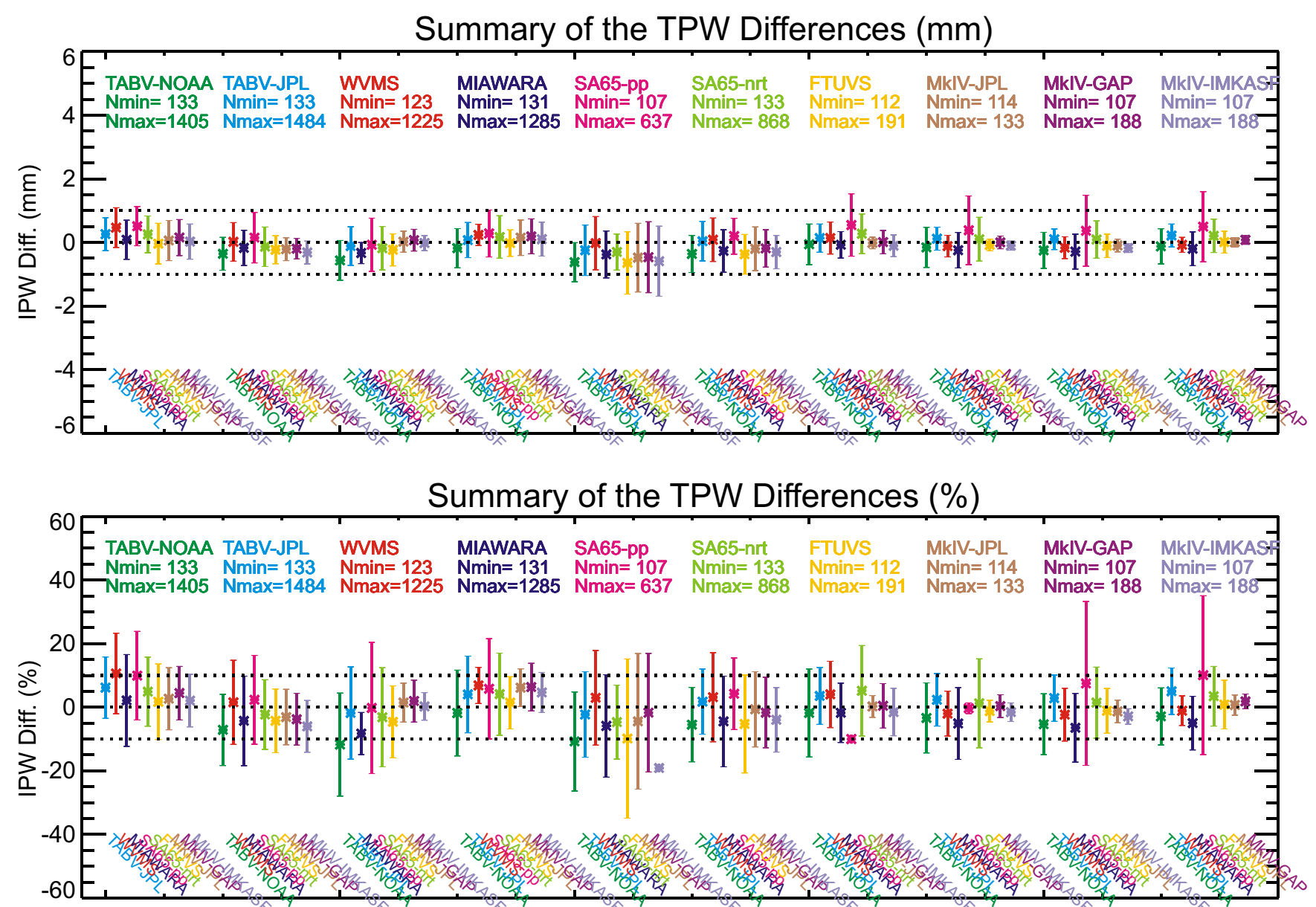

Fig. 15. Cross-comparison of all the TPW datasets available during MOHAVE-2009. The symbols indicate the difference between the dataset listed in the upper part of each plot (where the min and max number of coincidences are listed) and those listed in the lower part. The vertical bars indicate the spread of these differences See text for details. Use the colors for a better identification of the datasets: dark green $=\mathrm{TABV}$ NOAA solution, cyan = TABV-JPL solution, red = WVMS, navy = MIAWARA-C, pink = SuomiNet - PP solution, light green $=$ SuomiNet NRT solution, yellow $=$ FTUVS, brown $=$ MkIV-JPL solution, purple $=$ MkIV-GAP solution, and blue $=$ MkIV-IMKASF solution.

11-28 October 2009. One particular focus was the validation of the water vapor measurements of three Raman lidars including one permanently deployed at TMF (TMW) and the other two specially deployed at TMF for the campaign (ALVICE and STROZ). Another focus was the validation of a new portable microwave instrument (MIAWARA-C), the validation of a new version of the NOAA-Frost Point Hygrometer, and the validation of tropospheric water vapor profiles retrieved from a Fourier-Transform Spectrometer (MkIV). Forty-four balloons were launched throughout the campaign, which allowed twenty Frost-Point Hygrometer profiles (16 CFH and 4 NOAA-FPH, valid range from the ground to $27 \mathrm{~km}$ ) and 58 PTU radiosonde profiles (Vaisala RS92, valid range from the ground to about $10 \mathrm{~km}$, or to $18 \mathrm{~km}$ with corrections applied). By combining all available datasets, the full atmosphere from the ground to $80 \mathrm{~km}$ was covered. Satellite measurements (Aura-MLS, AIRS, TES, ENVISAT-MIPAS, and ACE), surface mete- orological measurements (MAWS, THref), and numerical modeling (MIMOSA) complemented the balloon-borne in-situ and ground-based remote sensing measurements. Finally, six independent ground-based instruments (2 GPS, 2 microwave radiometers, 2 FTS) led to the comparison of 10 simultaneous, automated and quasi-continuous TPW datasets.

In the troposphere and UTLS, the water vapor mixing ratio profiles measured by the Frost-Point hygrometers (CFH and NOAA-FPH) were again considered the most reliable and taken as reference, although during the campaign, their derivation revealed additional uncertainty associated with the uncertainty of the needed radiosonde pressure readings. The Vaisala RS92 and iMet-1 radiosonde temperature readings were found to differ by 0.2 to $0.9 \mathrm{~K}$, depending on altitude, the InterMet radiosonde being colder. The InterMet radiosonde humidity measurements were found unreliable and were not considered in the present comparisons. As expected 

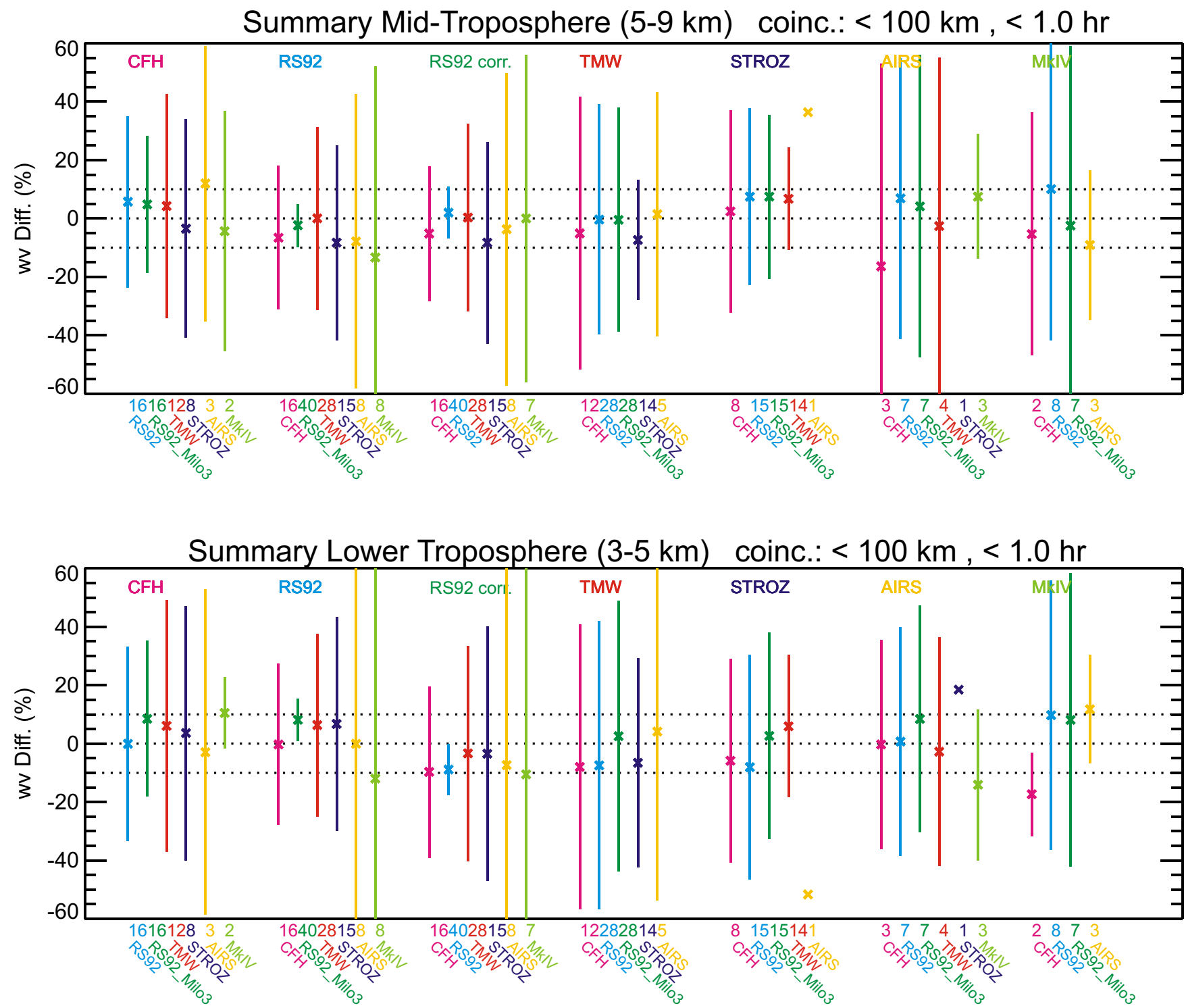

Fig. 16. Cross-comparison of the water vapor datasets available in the lower troposphere (bottom) and mid-troposphere (top) during MOHAVE-2009. The symbols indicate the differences (in \%) between the measurement listed in the upper part of each plot and those listed in the lower part (where the number of coincidences is listed). The vertical bars indicate the spread the differences (r.m.s.). Use the colors to better identify the datasets.

from numerous previous campaigns, the RS92 humidity measurements agreed very well with those from the frostpoint hygrometers $( \pm 5 \%)$ up to about $10 \mathrm{~km}$, then became too dry in the cold upper troposphere (up to $-50 \%$ ). This dry bias is reduced to $15 \%$ or less in the UTLS when the timelag and empirical corrections, as described by Miloshevich et al. (2009), are applied.

All three operating Raman lidars performed well below $10 \mathrm{~km}$ with biases with $\mathrm{CFH}$ and radiosonde not exceeding $\pm 4 \%$. However, only one (TMW) of these lidar systems performed well above $10-15 \mathrm{~km}$ as fluorescence was found to be contaminating the signals of the two others (ALVICE and
STROZ). The ALVICE lidar group provided an empiricallycorrected version of their data allowing them to extend the range to $15-20 \mathrm{~km}$, though these corrected profiles should be interpreted with caution since they are not independent from the CFH measurements. The lessons learned from this third MOHAVE campaign again pointed towards the critical need for experimentally removing fluorescence from the lidar receiver if one wants to guarantee independent measurements in the UTLS. Nonetheless, it also pointed out that fluorescence-free measurements from a well optimized Raman lidar system can indeed reach altitudes of $15-20 \mathrm{~km}$ with limited integration times ( 2 to $6 \mathrm{~h})$. In particular, the 

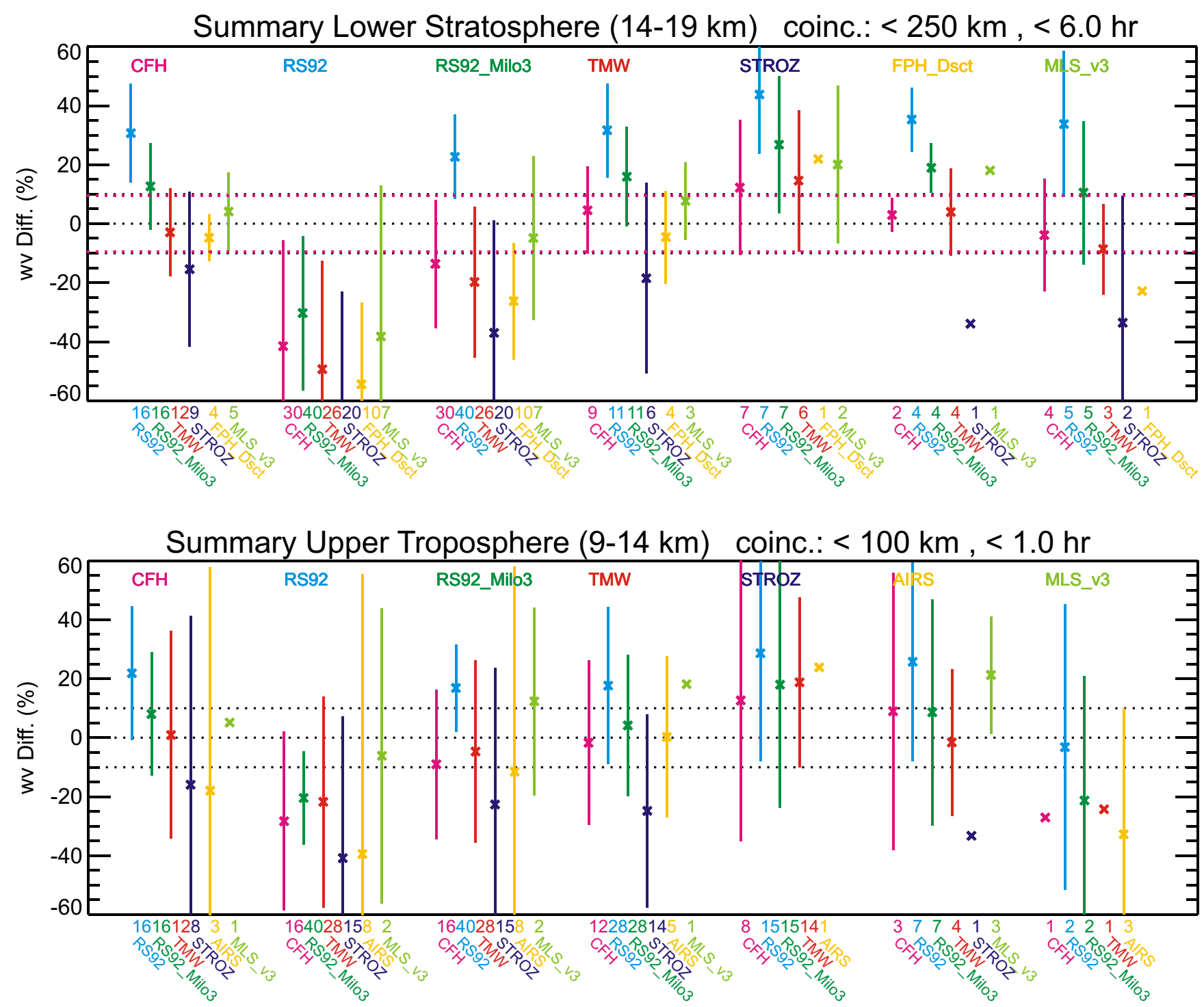

Fig. 17. Same as Fig. 16, but for the upper troposphere (bottom) and lower stratosphere (top).

TMW profiles remained within $\pm 4 \%$ of the $\mathrm{CFH}$ profiles up to the lidar detection limit, i.e., $14 \mathrm{~km}$ for 1-h integration times and $20 \mathrm{~km}$ for 2- to 6-h integration times. Anticipated technology advances such as enhanced laser power and enhanced optical and quantum efficiencies of typical lidar receiver components provide a high level of confidence in the critical role that this technique may have in the future for the long-term monitoring of water vapor in the UTLS. The lidars have proved here that they can easily outperform the radiosondes in the UTLS and though their precision is not yet as good as that of the Frost-point hygrometers, they have the advantage over the balloon-borne instrument to track atmospheric variability throughout the night. The dual water vapor and ozone lidar observations of a deep stratospheric intrusion on 20 October 2009 illustrate well this potential.
Figures 16 shows cross-comparisons of all the water vapor datasets available in the lower (bottom panel) and mid- (top panel) troposphere. The symbols indicate the percent difference between the instrument listed in the upper part of each panel and those listed in the bottom part (where the number of coincidences is listed). The colors can be used to easily identify each instrument. The vertical bars indicate the spread of these differences (r.m.s.). Note that at these altitudes, the water vapor measured standard deviations are well above $60 \%$, often at very short timescales and small horizontal scales (a few hours, a few tens of kilometers), so that r.m.s. values of $\pm 30 \%$ are not surprising, even when considering instruments of very good quality. Figure 17 shows similar cross-comparisons for the upper troposphere (bottom panel) and lower stratosphere (top panel). 

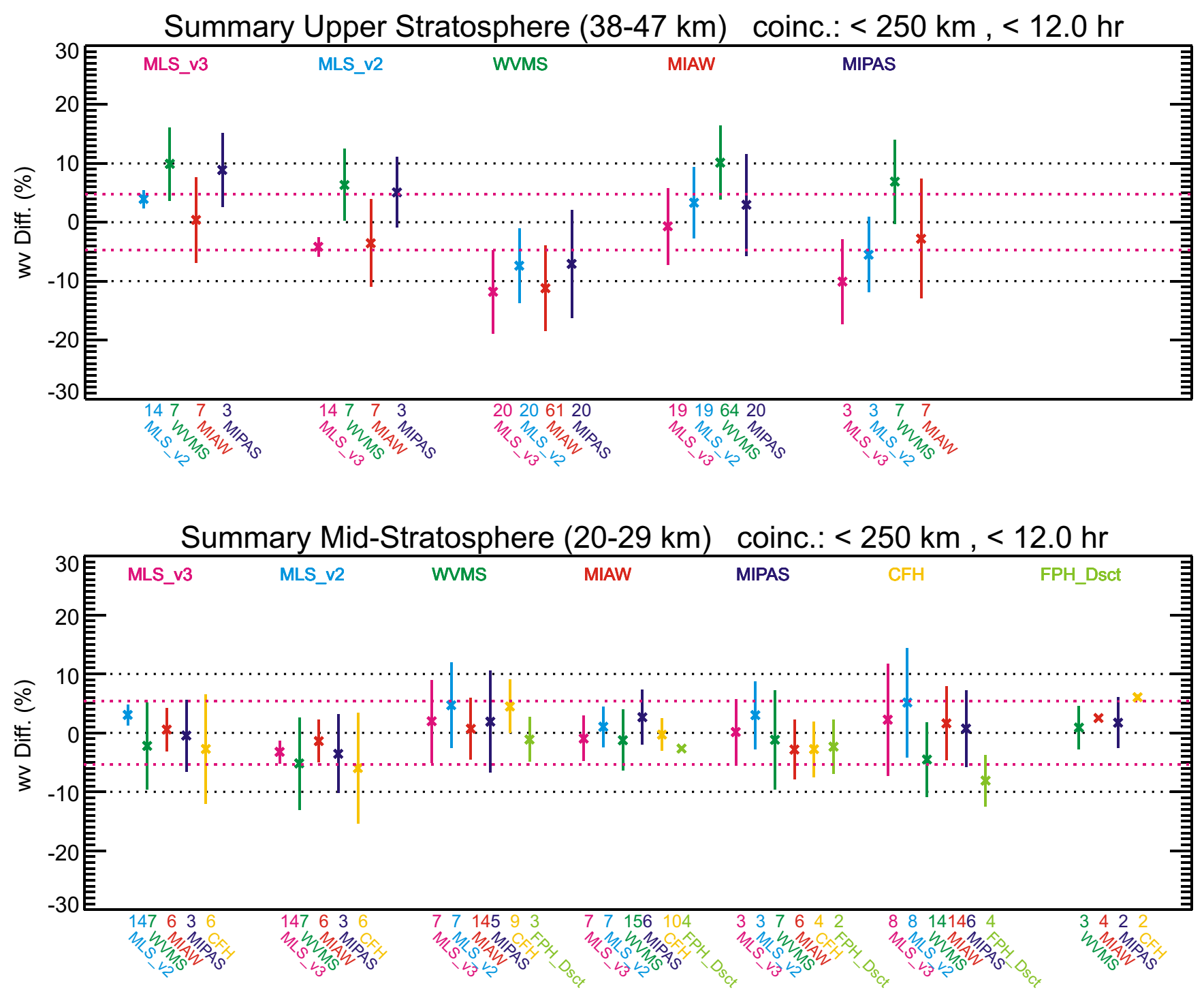

Fig. 18. Same as Fig. 16, but for the mid- (bottom) and upper (top) stratosphere.

The top panel of this figure (lower stratosphere) appears to be the most interesting one. The dry bias of the uncorrected RS92 mentioned before is obvious here (between $-30 \%$ and $-60 \%$ with respect to all other instruments). Note that the measured water vapor standard deviation is represented by two horizontal pink dotted curves near $\pm 10 \%$. The position of the symbols with respect to these lines, as well as the size of the vertical bars, provides important insight on how representative the measurements are. For example, the best agreement and smallest spread of the differences is seen when comparing the CFH and NOAA-FPH (short, yellow segment on the far left of the top panel). This confirms that the frost-point technique remains the most accurate in this region. Another interesting example is CFH vs. TMW (red symbol and segment on the far left of the top panel). The mean difference is very small $(-3 \%)$, but the spread is larger than that just discussed. This can be explained by the poor precision of TMW at this altitude compared to the frost-point technique.

In the stratosphere, water vapor is naturally much less variable and typically at values close to the Frost-point hygrometers' and MLS's uncertainties. The associated timescales are also larger than the duration of the MOHAVE campaign. As a result, the comparisons between all stratospheric sounders (CFH, NOAA-FPH, Aura-MLS, MIPAS, MIAWARA-C, and WVMS) allowed the identification of only the largest systematic differences, namely the 5-10\% dry bias of the WVMS microwave radiometer with MIAWARA-C and MLS v3. No other statistically significant biases could be observed. The four panels of Figs. 18 and 19 show the crosscomparisons between all available techniques in the stratosphere and lower mesosphere. Water vapor variability estimated by the standard deviations measured by MLS and $\mathrm{CFH}$, is again represented by the dotted pink curves $( \pm 5 \%$ 

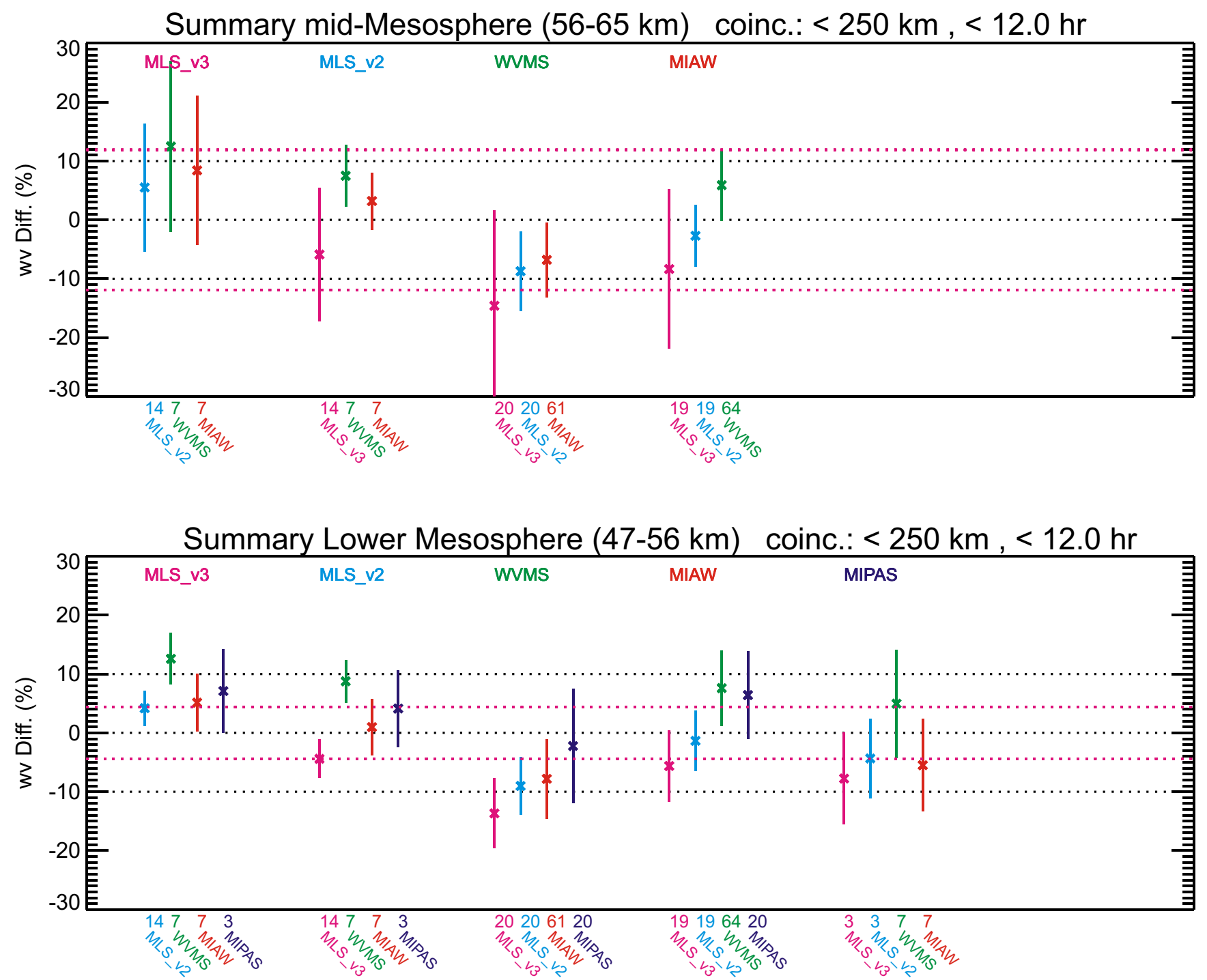

Fig. 19. Same as Fig. 16, but for the lower (bottom) and mid- (top) mesosphere.

to $\pm 12 \%)$. In the lower stratosphere (20-29 km, Fig. 18b), the mean difference between CFH (ascent-only) and NOAAFPH (descent-only) is about $6 \%$, a fraction of which $(2 \%)$ is owed to the different type of radiosonde used for the derivation of water vapor mixing ratio. The RS92 data are not available during balloon descent, resulting in the use of the InterMet pressure data by the NOAA-FPH. The difference between CFH and NOAA-FPH during balloon ascent, i.e., when both hygrometers can use the RS92 data, was found to be around $4 \%$ (not shown). In the upper stratosphere and lower mesosphere, the WVMS dry bias is slightly outside the variability limits. For all other instruments, the vertical bars (spread of the differences) almost always cross the "zero" line, indicating that these differences are not statistically significant (and also remain within the reported uncertainties).
A compilation of all comparisons was assembled in Fig. 20. CFH and MLS v3 were taken as the reference in the troposphere and stratosphere respectively. The top and bottom panels are purposely shifted horizontally to graphically mitigate the 3\%-7\% bias between MLS and CFH. The grey dotted curves again indicate water vapor variability estimated from the measured standard deviations.

Finally, a number of ground-based instruments provided Total Precipitable Water (TPW) measurements. All ten TPW datasets were found to remain within $5-10 \%$ of each other (Fig. 15). It is a clear demonstration of the level of maturity reached by the GPS, microwave and FTS techniques for TPW measurements. It also provides new confidence in the use of such techniques for a concurrent/alternate calibration method for water vapor Raman lidars, traditionally calibrated using radiosonde. 

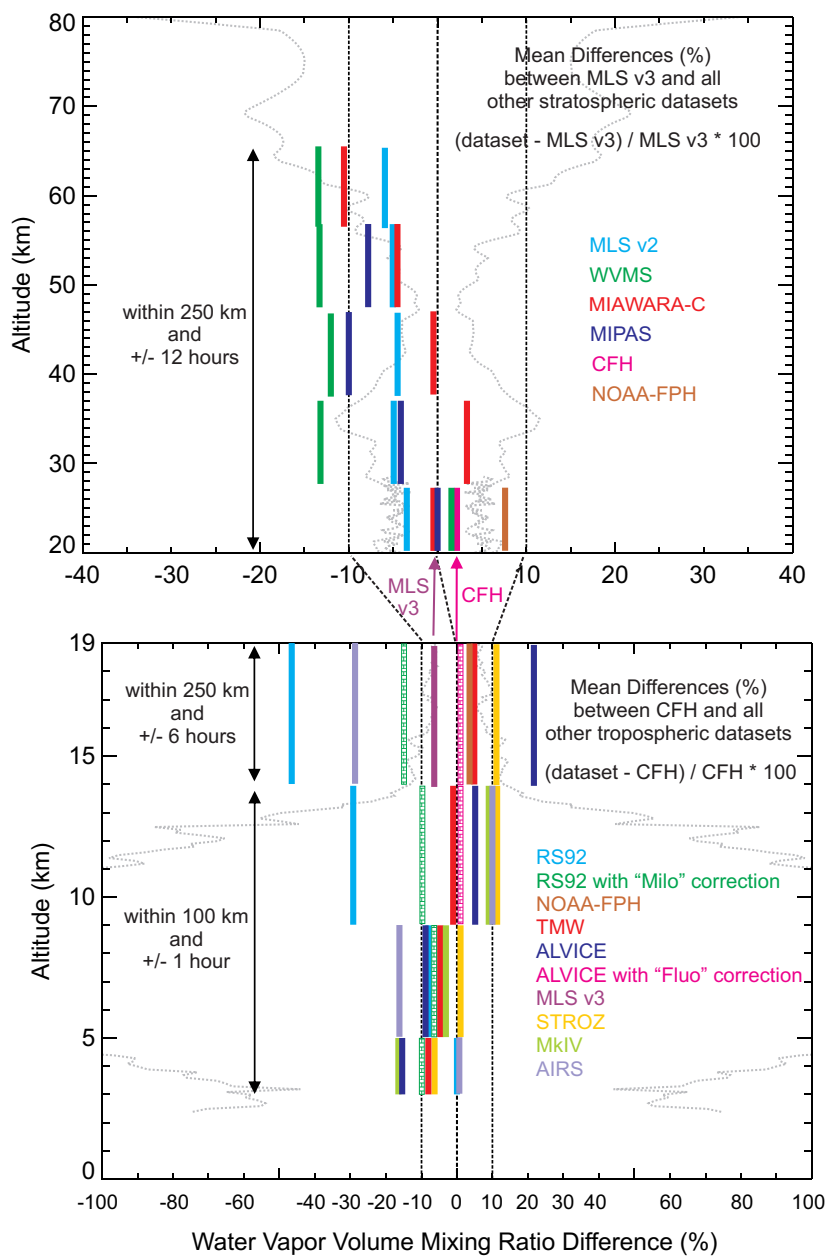

Fig. 20. Campaign-mean differences between all available datasets. CFH (respectively MLS v3) is taken as the reference in the troposphere (bottom panel) (respectively, stratosphere, top panel). The grey dotted curves show water vapor variability (\%) estimated from the standard deviations measured by CFH and MLS over the entire campaign. The top and bottom panels are purposely shifted horizontally to mitigate the 3-7\% difference between the tropospheric and stratospheric reference.

From a lidar standpoint, the MOHAVE-2009 campaign was very successful. Not only did it reveal again how careful the measurements must be made in order to optimize signalto-noise ratios and avoid fluorescence, but it also showed that a co-located GPS, microwave or FTS can be very useful to insure calibration stability over the long-term. These results in particular provided important insight into the design and optimization of the NDACC water vapor lidar measurement protocols, as well as in other global initiatives such as the GCOS Reference Atmosphere Network (GRUAN), and the Global Energy and Water Cycle Experiment (GEWEX). Yet it showed that systematic quality control must be made for Raman lidar measurements in the UTLS as they appear to be easily subject to contamination by fluorescence. The plan- ning of regular blind intercomparisons with robust measurement techniques such as the Frost-Point hygrometer is among the possible actions to take to prevent the inclusion of contaminated data in critical databases. A careful design of (or upgrade to) an instrumental setup insuring fluorescence-free signals must be considered the highest priority to insure a meaningful contribution to long-term records in the UTLS.

Acknowledgements. The work described in this paper was carried out at the Jet Propulsion Laboratory, California Institute of Technology, under agreements with the National Aeronautics and Space Administration. The data used here were made publicly available on JPL's MOHAVE-2009 website: http://tmf-lidar.jpl.nasa.gov/campaigns/mohave2009.htm. This campaign was partially funded by the NASA Upper Atmosphere Research Program. Part of the operations was supported by an appointment to the NASA Postdoctoral Program at the Goddard Space Flight Center, administered by Oak Ridge Associated Universities through a contract with NASA. The work by KIT was partly funded by the German Federal Ministry of Education and Research under contract no. 50EE0901. The authors acknowledge ESA for providing MIPAS L1b data. SuomiNet work is supported by the National Science Foundation under grant AGS-0918398.

Edited by: G. Pappalardo

\section{References}

Barrett, E. W., Herndon, L. R., and Carter, H. G.: Some Measurements of the Distribution of Water Vapor in the Stratosphere1, Tellus, 2, 302-311, 1950.

Bevis, M., Businger, S., Herring, T. A., Rocken, C., Anthes, R. A., and Ware, R. H.: GPS meteorology: Remote sensing of atmospheric water vapor using the global positioning system. J. Geophys. Res., 97, 15787-15801, 1992.

Bevis, M., Businger, S., Chiswell, S., Herring, T. A., Anthes, R. A., Rocken, C., and Ware, R. H.: GPS Meteorology: Mapping Zenith Wet Delays onto Precipitable Water, J. Appl. Meteorol., 33, 379-386, 1994.

Brewer, A. W., Cwilong, B., and Dobson, G. M. B.: Measurement of Absolute Humidity in Extremely Dry Air, Proc. Phys. Soc., 60, 52-70, 1948.

Cageao, R. P., Blavier, J.-F., McGuire, J. P., Jiang, Y., Nemtchinov, V., Mills, F. P., and Sander, S. P.:, High-resolution Fouriertransform ultraviolet-visible spectrometer for the measurement of atmospheric trace species: application to $\mathrm{OH}$, Appl. Opt., 40, 2024-203, 2001.

Dach, R., Hugentobler, U., Fridez, P., and Meindl, M.: Bernese GPS Software Version 5.0, 640 pp., University of Berne, 2007.

Forster, P. M. and Shine, K. P.: Stratospheric water vapour changes as a possible contributor to observed stratospheric cooling, Geophys. Res. Lett., 26, 3309-3312, 1999.

Fang, P. and Bock, Y.: A sliding-window procedure for super near real-time continuous GPS water vapor estimation using predicted orbits. Ann. Geophys., 16 (Suppl. I), C376, doi:10.1029/98GL02755, 1998.

Fetzer, E. J., Read, W. G., Waliser, D., Kahn, B. H., Tian, B., Vömel, H., Irion, F. W., Su, H., Eldering, A., de la Torre Juarez, 
M., Jiang, J., and Dang, V.: Comparison of upper tropospheric water vapor observations from the Microwave Limb Sounder and Atmospheric Infrared Sounder, J. Geophys. Res., 113, D22110, 10.1029/2008jd010000, 2008.

Fueglistaler, S., Dessler, A. E., Dunkerton, T. J., Folkins, I., Fu, Q., and Mote, P. W.: Tropical tropopause layer, Rev. Geophys., 47, RG1004, doi:10.1029/2008RG000267, 2009

Hasebe, F., Fujiwara, M., Nishi, N., Shiotani, M., Vömel, H., Oltmans, S., Takashima, H., Saraspriya, S., Komala, N., and Inai, Y.: In situ observations of dehydrated air parcels advected horizontally in the Tropical Tropopause Layer of the western Pacific, Atmos. Chem. Phys., 7, 803-813, doi:10.5194/acp-7-803-2007, 2007.

Hauchecorne, A., Godin, S., Marchand, M., Heese, B., and Souprayen, C.: Quantification of the transport of chemical constituents from the polar vortex to midlatitudes in the lower stratosphere using the high-resolution advection model MIMOSA and effective diffusivity, J. Geophys. Res., 107, 8289, doi:10.1029/2001JD000491, 2002.

Hurst, D. F., Oltmans, S. J., Vömel, H., Rosenlof, K. H., Davis, S. M., Ray, E. A., Hall, E. G., and Jordan, A. F.: Stratospheric water vapor trends over Boulder, Colorado: Analysis of the 30 year Boulder record, J. Geophys. Res., 116, D02306, doi:10.1029/2010JD015065, 2011a.

Hurst, D. F., Hall, E. G., Jordan, A. F., Miloshevich, L. M., Whiteman, D. N., Leblanc, T., Walsh, D., Vömel, H., and Oltmans, S. J.: Comparisons of temperature, pressure and humidity measurements by balloon-borne radiosondes and frost point hygrometers during MOHAVE 2009, Atmos. Meas. Tech. Discuss., 4, 43574401, doi:10.5194/amtd-4-4357-2011, 2011b.

Kley, D., Smit, H. G. J., Vömel, H., Grassl, H., Ramanathan, V., Crutzen, P. J., Williams, S., Meywerk, J., and Oltmans, S. J.: Tropospheric water-vapour and ozone cross-sections in a zonal plane over the central equatorial Pacific Ocean, Q. J. Roy. Meteorol. Soc., 123, 2009-2040, 1997.

Leblanc, T., McDermid, I. S., and Aspey, R. A.: First-Year Operation of a New Water Vapor Raman Lidar at the JPL Table Mountain Facility, California, J. Atmos. Ocean. Technol., 25, 14541462, 2008.

Leblanc, T., McDermid, I. S., and Walsh, T. D.: Ground-based water vapor Raman lidar measurements up to the upper troposphere and lower stratosphere - Part 2: Data analysis and calibration for long-term monitoring, Atmos. Meas. Tech. Discuss., 4, 51115145, doi:10.5194/amtd-4-5111-2011, 2011a.

Leblanc, T., Hauchecorne, A., Walsh, T. D., and McDermid, I. S.: Simultaneous Ozone and Water Vapor Lidar Observations and Modeling of a Stratospheric Intrusion during the MOHAVE2009 Campaign, J. Geophys. Res., submitted, 2011b.

Mattioli, V., Westwater, E. R., Cimini, D., Liljegren, J. S., Lesht, B. M., Gutman, S. I., and Schmidlin, F. J.: Analysis of radiosonde and ground-based remotely sensed PWV data from the 2004 North Slope of Alaska Arctic Winter Radiometric Experiment. J. Atmos. Ocean. Technol., 24, 415-431, 2007.

McDermid, I. S., Leblanc, T., and Walsh, T. D.: Ground-based water vapor Raman lidar measurements up to the upper troposphere and lower stratosphere - Part 1: Instrument development, optimization, and validation, Atmos. Meas. Tech. Discuss., 4, 50795109, doi:10.5194/amtd-4-5079-2011, 2011.

McGee, T. J., Whiteman, D., Ferrare, R., Butler, J. J., and Burris, J.
F.: STROZ LITE - STRatospheric OZone Lidar Trailer Experiment, Opt. Eng., 30, 31-39, 1991

McGee, T. J., Gross, M. R., Singh, U. N., Butler, J. J., and Kimvilakani, P. E.: Improved Stratospheric Ozone Lidar, Opt. Eng., 34, 1421-1430, 1995

McGee, T. J., Twigg, L., and Sumnicht, G.: STROZ Measurments during MOHAVE-2009, Atmos. Meas. Technol., in preparation, 4 (this issue), 2011.

Miloshevich, L. M., Paukkunen, A., Vömel, H., and Oltmans, S. J.:, Development and Validation of a Time-Lag Correction for Vaisala Radiosonde Humidity Measurements, J. Atmos. Ocean. Technol., 21, 1305-1327, 2004.

Miloshevich, L. M., Vömel, H., Whiteman, D. N., Lesht, B. M., Schmidlin, F. J., and Russo, F.: Absolute accuracy of water vapor measurements from six operational radiosonde types launched during AWEX-G and implications for AIRS validation, J. Geophys. Res., 111, D09S10, doi:10.1029/2005JD006083, 2006.

Miloshevich, L. M., Vömel, H., Whiteman, D. N., and Leblanc, T.: Accuracy assessment and correction of Vaisala RS92 radiosonde water vapor measurements, J. Geophys. Res., 114, D11305, doi:10.1029/2008JD011565, 2009.

Nedoluha, G. E., Bevilacqua, R. M., Gomez, R. M., Thacker, D. L., Waltman, W. B., and Pauls, T. A.: Ground-based measurements of water vapor in the middle atmosphere, J. Geophys. Res., 100, 2927-2939, 1995.

Nedoluha, G. E., Gomez, R. M., Hicks, B. C., Wrotny, J. E., Boone, C., and Lambert, A.: Water vapor measurements in the mesosphere from Mauna Loa over solar cycle 23, J. Geophys. Res., 114, D23303, doi:10.1029/2009jd012504, 2009.

Nedoluha, G. E., Gomez, R. M., Hicks, B. C., Helmboldt, J., Bevilacqua, R. M., and Lambert, A.: Ground-based microwave measurements of water vapor from the midstratosphere to the mesosphere, J. Geophys. Res., 116, D02309, doi:10.1029/2010JD014728, 2011.

Oltmans, S. J. and Hofmann, D. J.: Increase in lower-stratospheric water-vapor at a mid-latitude Northern-Hemisphere site from 1981 to 1994, Nature, 374, 146-149, 1995.

Oltmans, S. J., Vömel, H., Hofmann, D. J., Rosenlof, K H., and Kley, D.: The increase in stratospheric water vapor from balloonborne, frostpoint hygrometer measurements at Washington, D.C., and Boulder, Colorado, Geophys. Res. Lett., 27, 34533456, 2000.

Randel, W. J., Wu, F., Vömel, H., Nedoluha, G. E., and Forster, P.: Decreases in stratospheric water vapor after 2001: Links to changes in the tropical tropopause and the Brewer-Dobson circulation, J. Geophys. Res., 111, D12312, doi:10.1029/2005jd006744, 2006

Read, W. G., Lambert, A., Bacmeister, J., Cofield, R. E., Christensen, L. E., Cuddy, D. T., Daffer, W. H., Drouin, B. J., Fetzer, E., Froidevaux, L., Fuller, R., Herman, R., Jarnot, R. F., Jiang, J. H., Jiang, Y. B., Kelly, K., Knosp, B. W., Kovalenko, L. J., Livesey, N. J., Liu, H. C., Manney, G. L., Pickett, H. M., Pumphrey, H. C., Rosenlof, K. H., Sabounchi, X., Santee, M. L., Schwartz, M. J., Snyder, W. V., Stek, P. C., Su, H., Takacs, L. L., Thurstans, R. P., Vömel, H., Wagner, P. A., Waters, J. W., Webster, C. R., Weinstock, E. M., and Wu, D. L.: Aura Microwave Limb Sounder upper tropospheric and lower stratospheric $\mathrm{H}_{2} \mathrm{O}$ and relative humidity with respect to ice validation, J. Geophys. Res., 112, D24S35, doi:10.1029/2007jd008752, 2007 
Revercomb, H. E., Turner, D. D., Tobin, D. C., Knuteson, R. O., Feltz, W. F., Barnard, J., Bösenberg, J., Clough, S., Cook, D., Ferrare, R., Goldsmith, J., Gutman, S., Halthore, R., Lesht, B., Liljegren, J., Linné, H., Michalsky, J., Morris, V., Porch, W., Richardson, S., Schmid, B., Splitt, M., Van Hove, T., Westwater, E., and Whiteman, D.: The Arm Program's Water Vapor Intensive Observation Periods, B. Am. Meteorol. Soc., 84, 217-236, doi:10.1175/bams-84-2-217, 2003.

Salasmaa, E. and Kostamo, P.: New thin film humidity sensor, in: Proc. of Third Symposium on Meteorological Observations and Instrumentation, Washington, DC, Am. Meteor. Soc., 33-38, 1975.

Schneider, M., Toon, G. C., Blavier, J.-F., Hase, F., and Leblanc, T.: $\mathrm{H}_{2} \mathrm{O}$ and $\delta \mathrm{D}$ profiles remotely-sensed from ground in different spectral infrared regions, Atmos. Meas. Tech., 3, 1599-1613, doi:10.5194/amt-3-1599-2010, 2010.

Shibata, T., Vömel, H., Hamdi, S., Kaloka, S., Hasebe, F., Fujiwara, M., and Shiotani, M.: Tropical cirrus clouds near cold point tropopause under ice supersaturated conditions observed by lidar and balloon-borne cryogenic frost point hygrometer, J. Geophys. Res., 112, D03210, doi:10.1029/2006jd007361, 2007.

Smith, T. L., Benjamin, S. G., and Gutman, S. I.: Short-range forecast impact from assimilation of GPS-IPW observations into the Rapid Update Cycle, Mon. Weather Rev., 135, 2914-2930, doi:10.1175/MWR3436.1, 2007.

Stiller, G. P., Kiefer, M., Eckert, E., von Clarmann, T., Kellmann, S., García-Comas, M., Funke, B., Leblanc, T., Fetzer, E., Froidevaux, L., Gomez, M., Hall, E., Hurst, D., Jordan, A., Kämpfer, N., Lambert, A., McDermid, I. S., McGee, T., Miloshevich, L., Nedoluha, G., Read, W., Schneider, M., Schwartz, M., Straub, C., Toon, G., Twigg, L. W., Walker, K., and Whiteman, D. N.: Validation of MIPAS IMK/IAA temperature, water vapor, and ozone profiles with MOHAVE-2009 campaign measurements, Atmos. Meas. Tech. Discuss., 4, 4403-4472, doi:10.5194/amtd4-4403-2011, 2011.

Straub, C., Murk, A., and Kämpfer, N.: MIAWARA-C, a new ground based water vapor radiometer for measurement campaigns, Atmos. Meas. Tech., 3, 1271-1285, doi:10.5194/amt-31271-2010, 2010.

Suortti, T. M., Kivi, R., Kats, A., Yushkov, V., Kmpfer, N., Leiterer, U., Miloshevich, L. M., Neuber, R., Paukkunen, A., Ruppert, P., and Vömel, H.: Tropospheric Comparisons of Vaisala Radiosondes and Balloon-Borne Frost-Point and Lyman- $\alpha$ Hygrometers during the LAUTLOS-WAVVAP Experiment, J. Atmos. Ocean. Technol., 25, 149-166, 2008.

Thomas, I. D., King, M. A., Clarke, P. J., and Penna, N. T.: Precipitable water vapor estimates from homogeneously reprocessed GPS data: An intertechnique comparison in Antarctica, J. Geophys. Res., 116, D04107, doi:10.1029/2010jd013889, 2011.

Toon, G. C.: The JPL MkIV interferometer, Opt. Photon. News, 2, 19-21, 1991.

Toon, G. C., Blavier, J.-F., Leblanc, T., Pongetti, T., Sander, S., Schneider, S., and Gutman, S.: Ground-based atmospheric measurements by the JPL MkIV interferometer during MOHAVE2009, Atmos. Meas. Technol. Disc., in preparation, 4, this issue, 2011.

Turner, D. D. and Goldsmith, J. E. M.: Twenty-Four-Hour Raman Lidar Water Vapor Measurements during the Atmospheric Radiation Measurement Program's 1996 and 1997 Water Vapor Inten- sive Observation Periods, J. Atmos. Ocea. Technol., 16, 10621076, 1999.

Vömel, H., Oltmans, S. J., Hofmann, D. J., Deshler, T., and Rosen, J. M.: The evolution of the dehydration in the Antarctic stratospheric vortex, J. Geophys. Res., 100, 13919-13926, 1995.

Vömel, H., David, D. E., and Smith, K.: Accuracy of tropospheric and stratospheric water vapor measurements by the cryogenic frost point hygrometer: Instrumental details and observations, J. Geophys. Res., 112, D08305, doi:10.1029/2006jd007224, 2007a.

Vömel, H., Barnes, J. E., Forno, R. N., Fujiwara, M., Hasebe, F., Iwasaki, S., Kivi, R., Komala, N., Kyrö, E., Leblanc, T., Morel, B., Ogino, S. Y., Read, W. G., Ryan, S. C., Saraspriya, S., Selkirk, H., Shiotani, M., Valverde Canossa, J., and Whiteman, D. N.: Validation of Aura Microwave Limb Sounder water vapor by balloon-borne Cryogenic Frost point Hygrometer measurements, J. Geophys. Res., 112, D24S37, doi:10.1029/2007jd008698, 2007b.

Vömel, H., Selkirk, H., Miloshevich, L., Valverde-Canossa, J., Valdés, J., Kyrö, E., Kivi, R., Stolz, W., Peng, G., and Diaz, J. A.: Radiation Dry Bias of the Vaisala RS92 Humidity Sensor, J. Atmos. Ocean. Technol., 24, 953-963, 2007c.

Wang, Z., Whiteman, D. N., Demoz, B. B., and Veselovskii, I.: "A new way to measure cirrus cloud ice water content using ice Raman scatter with Raman lidar", Geophys. Res. Let., 31, L15101, doi:10.1029/2004GL020004, 2004.

Ware, R. H., Fulker, D. W., Stein, S. A., Anderson, D. N., Avery, S. K., Clark, R. D., Droegemeier, K. K., Kuettner, J. P., Minster, J. B., and Sorooshian, S.: SuomiNet: A real-time national GPS network for atmospheric research and education, B. Am. Meteorol. Soc., 81, 677-694, 2000.

Whiteman, D. N. and Melfi, S. H.: Cloud liquid water, mean droplet radius and number density measurements using a Raman lidar, J. Geophys. Res., 104, 31411-31419, 1999.

Whiteman, D. N., Demoz, B., Di Girolamo, P., Comer, J., Veselovskii, I., Evans, K., Wang, Z., Cadirola, M., Rush, K., Schwemmer, G., Gentry, B., Melfi, S. H., Mielke, B., Venable, D., and Van Hove, T.: Raman Water Vapor Lidar Measurements During the International $\mathrm{H}_{2} \mathrm{O}$ Project. I. Instrumentation and Analysis Techniques, J. Atmos. Ocean. Technol., 23, 157-169, 2006.

Whiteman, D. N., Veselovskii, I., Cadirola, M., Rush, K., Comer, J., Potter, J., and Tola, R.: Demonstration Measurements of Water Vapor, Cirrus Clouds, and Carbon Dioxide Using a HighPerformance Raman Lidar, J. Atmos. Ocean. Technol., 24, 13771388, 2007.

Whiteman, D. N., Rush, K., Rabenhorst, S., Welch, W., Cadirola, M., McIntire, G., Russo, F., Adam, M., Venable, D., Connell, R., Veselovskii, I., Forno, R., Mielke, B., Stein, B., Leblanc, T., McDermid, S., and Vömel, H.: Airborne and Ground-Based Measurements Using a High-Performance Raman Lidar, J. Atmos. Oceanic Technol., 27, 1781-1801, doi:10.1175/2010jtecha1391.1, 2010.

Whiteman, D. N., Cadirola, M., Venable, D., Calhoun, M., Miloshevich, L., Vermeesch, K., Twigg, L., Dirisu, A., Hurst, D., Hall, E., Jordan, A., and Vömel, H.: The ALVICE system during MOHAVE-2009, Atmos. Meas. Technol., 4, in preparation, (this issue), 2011. 
Wolfe, D. and Gutman, S. I.: Developing an operational, surfacebased, GPS, water vapor observing system for NOAA: Network design and results, J. Atmos. Ocean. Technol., 17, 426-440, 2000 .
Wunch, D., Toon, G. C., Blavier, J.-F. L., Washenfelder, R. A., Notholt, J., Connor, B. J., Griffith, D. W. T., Sherlock, V., and Wennberg, P. O.: The Total Carbon Column Observing Network, Philos. T. R. Soc. A., 369, 2087-2112, doi:10.1098/rsta.2010.0240, 2011. 